\title{
The MMN as a viable and objective marker of auditory development in $\mathrm{Cl}$ users
}

\section{Näätänen, Risto}

2017-09

Näätänen , R , Petersen , B , Torppa , R , Lonka , E \& Vuust , P 2017 , ' The MMN as a viable and objective marker of auditory development in $\mathrm{Cl}$ users ', Hearing Research, vol. 353 , pp. 57-75 . https://doi.org/10.1016/j.heares.2017.07.007

http://hdl.handle.net/10138/298049

https://doi.org/10.1016/j.heares.2017.07.007

publishedVersion

Downloaded from Helda, University of Helsinki institutional repository.

This is an electronic reprint of the original article.

This reprint may differ from the original in pagination and typographic detail.

Please cite the original version. 
Review Article

\title{
The MMN as a viable and objective marker of auditory development in CI users
}

\author{
Risto Näätänen ${ }^{\mathrm{a}, \mathrm{d}}$, Bjørn Petersen ${ }^{\mathrm{b},{ }^{*} \text {, Ritva Torppa }}{ }^{\mathrm{c}, \mathrm{e}}$, Eila Lonka ${ }^{\mathrm{c}}$, Peter Vuust ${ }^{\mathrm{b}}$ \\ ${ }^{a}$ Center for Functionally Integrative Neuroscience (CFIN), Aarhus University, Aarhus, Denmark \\ ${ }^{\mathrm{b}}$ Center for Music in the Brain, Dept. of Clinical Medicine, Aarhus University \& The Royal Academy of Music Aarhus/Aalborg, Denmark \\ ${ }^{c}$ Department of Psychology and Logopedics, Faculty of Medicine, University of Helsinki, Finland \\ ${ }^{\mathrm{d}}$ Institute of Psychology, University of Tartu, Tartu, Estonia \\ ${ }^{\text {e }}$ Cognitive Brain Research Unit (CBRU), Faculty of Medicine, University of Helsinki, Finland
}

\section{A R T I C L E I N F O}

\section{Article history:}

Received 20 December 2016

Received in revised form

16 June 2017

Accepted 18 July 2017

Available online 20 July 2017

\section{Keywords:}

Cochlear implants (CI)

Central auditory processing

Mismatch negativity (MMN)

Neural plasticity

Speech perception

Music perception

\begin{abstract}
A B S T R A C T
In the present article, we review the studies on the use of the mismatch negativity (MMN) as a tool for an objective assessment of cochlear-implant $(\mathrm{CI})$ functioning after its implantation and as a function of time of $\mathrm{CI}$ use. The MMN indexes discrimination of different sound stimuli with a precision matching with that of behavioral discrimination and can therefore be used as its objective index. Importantly, these measurements can be reliably carried out even in the absence of attention and behavioral responses and therefore they can be extended to populations that are not capable of behaviorally reporting their perception such as infants and different clinical patient groups. In infants and small children with $\mathrm{CI}$, the MMN provides the only means for assessing the adequacy of the $\mathrm{Cl}$ functioning, its improvement as a function of time of $\mathrm{CI}$ use, and the efficiency of different rehabilitation procedures. Therefore, the MMN can also be used as a tool in developing and testing different novel rehabilitation procedures. Importantly, the recently developed multi-feature MMN paradigms permit the objective assessment of discrimination accuracy for all the different auditory dimensions (such as frequency, intensity, and duration) in a short recording time of about $30 \mathrm{~min}$. Most recently, such stimulus paradigms have been successfully developed for an objective assessment of music perception, too.
\end{abstract}

๑) 2017 Elsevier B.V. All rights reserved.

\section{Contents}

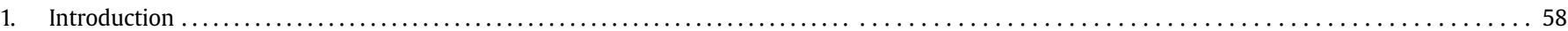

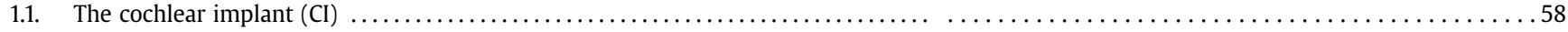

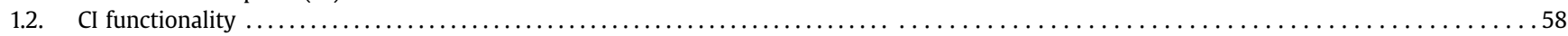

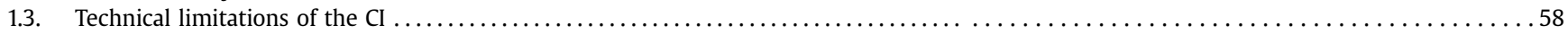

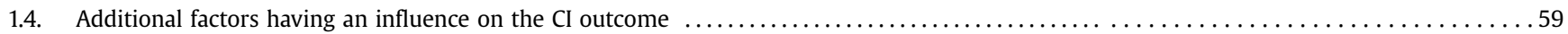

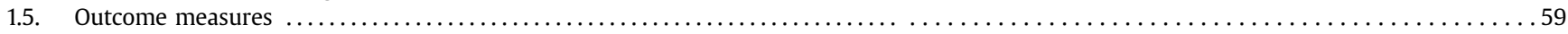

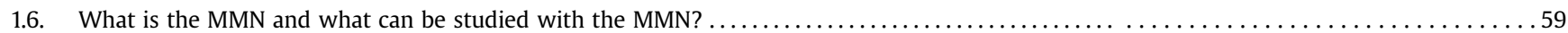

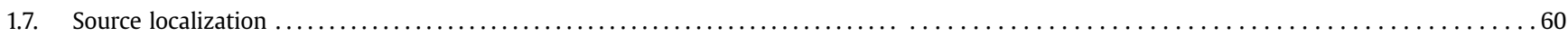

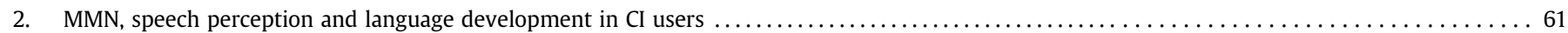

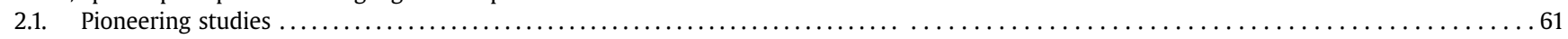

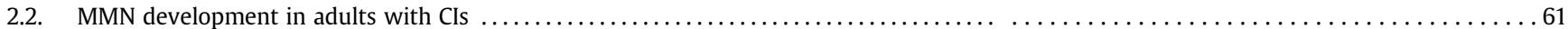

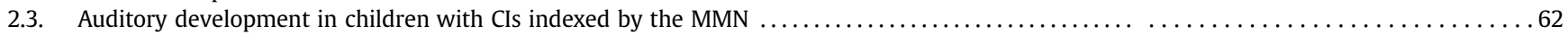

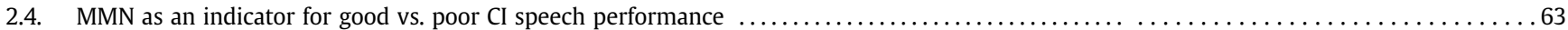

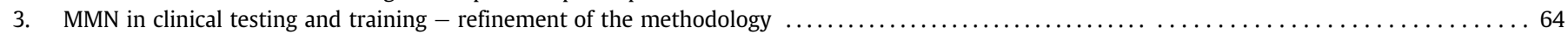

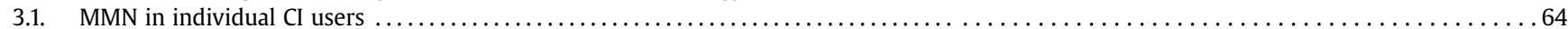

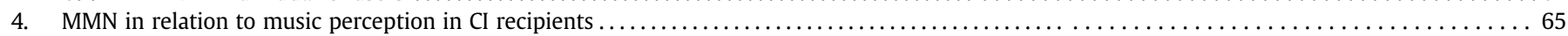

4.1. Results from odd-ball paradigms - neural responses for changes in musical syntax, timbre, attack time and melodic contour ...........66

\footnotetext{
* Corresponding author.
} 


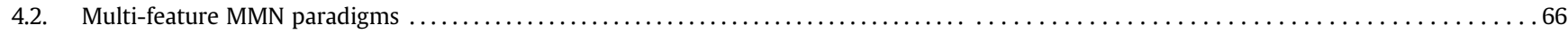

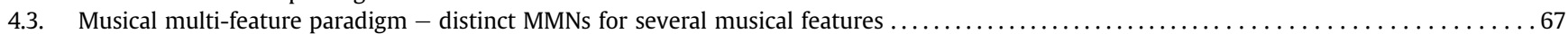

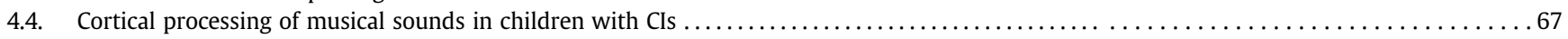

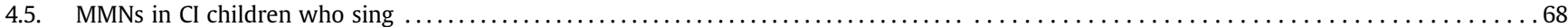

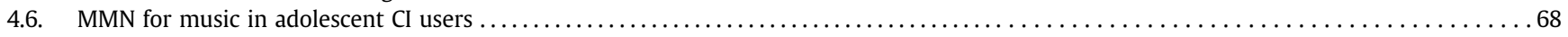

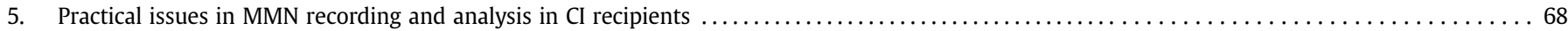

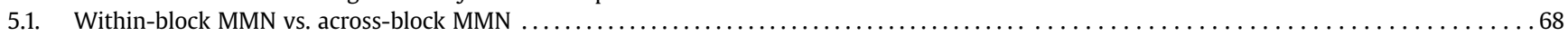

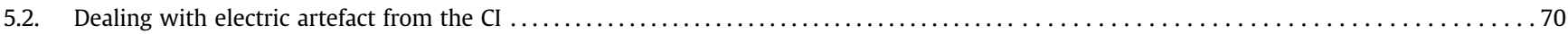

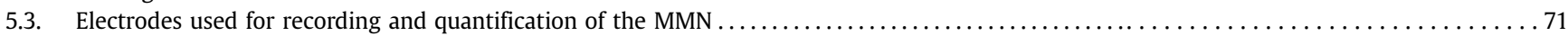

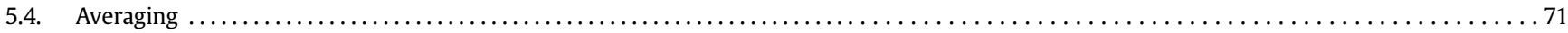

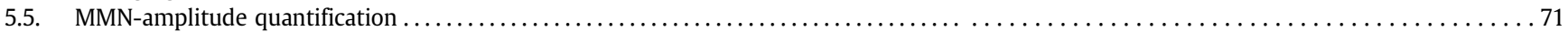

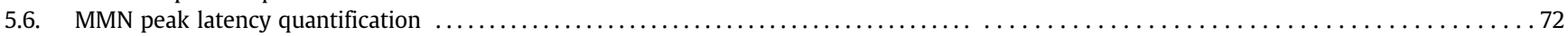

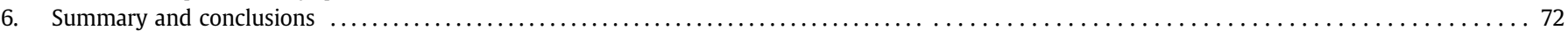

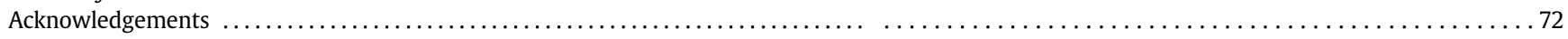

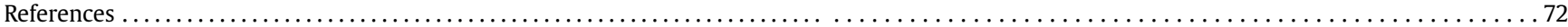

\section{Introduction}

\subsection{The cochlear implant (CI)}

The cochlear implant $(\mathrm{CI})$ is an electronic device that allows individuals with severe to profound hearing loss to gain or regain the sense of hearing. Over the last decades, the speech perception performance of adult $\mathrm{CI}$ recipients has progressed from poor openset word or sentence recognition to interactive conversation relying on audition alone (Gaylor et al., 2013; Fu and Galvin, 2008). A general rise in bilateral implantation and recent technological refinements have further improved implant outcomes, allowing not only postlingually deafened adults to restore speech comprehension but also children with profound congenital hearing loss to acquire spoken language (Limb and Rubinstein, 2012). Correspondingly, the number of $\mathrm{CI}$ surgeries has risen exponentially and today more than $350,000 \mathrm{CI}$ recipients use the device in their daily communication. As candidacy criteria continue to expand, it is likely that the number of $\mathrm{CI}$ recipients will increase into the foreseeable future (Carlson, 2015).

\subsection{CI functionality}

The principle of a $\mathrm{CI}$ includes $1-3$ microphones which direct the sounds from the environment to a sound processor in which the incoming signal undergoes a spectral analysis and is decomposed into different frequency bands or channels. In the next phase, information about each frequency band is conveyed by a radiofrequency transmitter, via a receiver, to an electrode array implanted within the cochlea. This way different auditory nerve fibers can be stimulated at different places in the cochlea. In accordance with the place coding mechanism, electrodes near the base of the cochlea are stimulated with high-frequency signals, while electrodes near the apex are stimulated with low-frequency signals (Wilson and Dorman, 2008; Nogueira et al., 2009; Hu and Loizou, 2008; Loizou 1999).

An essential element in this process is the processing strategy which handles the conversion of acoustic sound signals into electrical impulses. This involves components such as stimulation pattern, rate and pulse-width of the signal, filtering, stimulation thresholds and distribution of specific frequencies to the appropriate electrodes. These settings are determined in a programming procedure and are referred to as the patient's MAP or program, typically stored in user-selectable presets. In contemporary CIs three strategies are frequently used: 1) continuous interleaved sampling (CIS) (Wilson et al., 1991), 2) the advanced combinational encoder (ACE) (Kiefer et al., 2001) and 3) high resolution (HiRes) (Koch et al., 2007).

The CIS strategy provides continuous sampling of the envelope signals by rapidly presented pulses that are interleaved in time across electrodes. This interleaving eliminates a principal component of electrode interaction that is produced by summation of the electric fields in the cochlea from simultaneously stimulated electrodes (Wilson, 2015). The ACE strategy is similar to CIS with the main difference being that the number of electrodes stimulated is smaller than the total number of analysis channels. Using the spectral-maxima principle, ACE strategy continuously estimates the outputs of the filters and selects the 8-10 envelopes with the largest amplitude for stimulation (Loizou, 2006). The HiRes strategy is a close variation of CIS designed to increase the spectral and temporal resolution provided by the $\mathrm{CI}$. It uses relatively high rates of stimulation, relatively high cutoff frequencies for the envelope detectors and up to 16 processing channels and associated stimulus sites (Nogueira et al., 2009; Wilson and Dorman, 2008). The more recent HiRes120 uses current steering to control the electrical interaction. When two (or more) neighboring electrodes are stimulated in a suitable manner, intermediated channels, also known as virtual channels, are created between the electrodes (Koch et al., 2007). Other strategies used by different companies include the "fundamental frequency modulation" (F0mod) strategy (Francart et al., 2015; Milczynski et al., 2009; Laneau et al., 2006) and the "fine structure processing" (FSP) strategy (Hochmair et al., 2006; Arnoldner et al., 2007).

\subsection{Technical limitations of the CI}

Despite these technological advances and the fact that the device is designed such that it mimics the tonotopic organization of the healthy cochlea, electric hearing is not comparable to normal hearing. First, CIs are restricted to 12-22 electrodes that can hardly compensate for the functional loss of 3500 inner hair cells (Limb and Roy, 2014). Second, due to the spread of electric current from the active electrode to adjacent places, the electrodes do not function independently which limits the representation of the accurate place code for frequencies and spectral cues (Abbas et al. 2004; Chatterjee and Shannon, 1998). In many cases, this leads to mismatches between electrode place maps and optimal cochlear loci. In addition, the CI-signal typically lacks temporal fine structure, resulting especially in poor pitch perception (Ciocca et al., 2002; Oxenham, 2008).

Moreover, because of necessary compression of the sound signal, the dynamic range of the CI signal is limited to $6-30 \mathrm{~dB}$, 
compared to the potential NH range of $120 \mathrm{~dB}$ (Shannon, 1983; Moore and Moore, 2003; Zeng, 2004). Whereas many CI users achieve stunning speech perception in quiet listening conditions (Friesen et al., 2001; Wilson and Dorman, 2007), these technical limitations represent a number of challenges in less favorable conditions. In particular, many $\mathrm{Cl}$ listeners have difficulties with the perception of speech in background noise (Drennan and Rubinstein, 2008, for a review; regarding children, Asp et al., 2012; Caldwell and Nittrouer, 2013) and consonant and vowel perception (Geers, 2003 Donaldson and Kreft, 2006).

Finally, the poor perception of pitch and intensity has negative consequences for the perception of prosody (question vs. statement intonation, Peng et al., 2008; word and sentence stress, Torppa et al., 2014a; emotional prosody, Hopyan-Misakyan, 2009; Nakata et al., 2012) and for the perception of music (Limb and Roy, 2014; Torppa et al., 2014b; Agrawal, 2013; Timm et al., 2012; Petersen et al., 2012; Cooper et al., 2008; Gfeller et al., 2007; Olszewski et al., 2005; Mc Dermott and Looi, 2004; Leal et al., 2003;). The poor perception of prosody and the problems in the perception of phonemes can be detrimental, especially during language acquisition (Torppa et al., 2014a). These aspects may partially underlie the findings that for children with CIs (CI children), several aspects of language tend to develop less accurately than for $\mathrm{NH}$ children (Geers et al., 2016).

\subsection{Additional factors having an influence on the CI outcome}

An important aspect of cochlear implantation is the fact that a considerable variability remains in individual patient outcomes, with performance ranging from simple sound detection to the ability to converse on the phone (Fu and Galvin, 2008). The source of this heterogeneity lies in the number of different factors that may influence the post-operative performance. These include onset, duration and severity of the hearing loss, differences in the survival of the peripheral neural elements, residual acoustic hearing and device-related effects such as the position of the electrodes relative to neurons, design and form of the electrodes and sound processing strategy (Kral et al., 2016; van Dijk et al., 1999; Gantz et al., 1998; Wilson et al., 1993). Furthermore, factors such as central brain processing, cross-modal reorganization (recent review e.g. Lazard et al., 2014) and cognitive and language skills may exert a significant influence on outcome variability (review e.g. Kral and O'Donoghue, 2010; Kral et al., 2016). In the context of electrophysiological measures in cochlear implantation, this is particularly relevant since one of the main objectives is the possibility to differentiate auditory vs. non-auditory influences on the outcomes.

Importantly, as opposed to prelingually implanted children, in postlingually deafened CI-users, the auditory development has been shaped by prior hearing experience, helping them to process auditory information from the CI (Vavatzanidis et al., 2015; Torppa et al., 2012; Petersen et al., 2012; Caposecco et al., 2012). Thus, the limitations of CIs can be particularly critical for congenitally deaf children with CIs. However, if they receive their CIs before the first 3-5 years of life, the central auditory areas have the capacity to develop well after implantation (Kral and Sharma, 2012; Sharma et al., 2002, 2009).

With the exception of a few studies (Vavatzanidis et al., 2015; Torppa et al., 2012, 2014b), all MMN studies on CI children reviewed here involve older children or adolescents with a prolonged period (more than 3-5 years) of deafness (Table 1 ). The current practice, however, is to implant the children at around 1 year of age which may further promote their language skills (for a review see Vlastarakos et al., 2010). There is also evidence of bilateral cochlear implantation favoring near-normal spoken language development in CI children (Boons et al., 2012; Wie, 2010).
Furthermore, bimodal stimulation (hearing aid $+\mathrm{CI}$ ) might, according to tentative results (Lammers et al., 2014; Looi and Radford, 2011), promote spoken language skills.

\subsection{Outcome measures}

The CI outcome is typically measured by behavioral methods such as sentence or word recognition and the identification of speech in background noise (e.g., Holden et al., 2013). Whereas these methods are compulsory in terms of measuring CI functioning and user outcome, they provide limited information regarding the cortical changes which underlie the recovery of hearing after cochlear implantation. For that purpose, objective neuroimaging methods such as the fMRI, the PET, the EEG and the MEG are in demand. Historically, CIs were not considered compatible with the powerful magnetic fields generated by MR scanners, representing potential risks of patient injury. Recent technological advances, however, have made it possible to perform diagnostic MRI with CI patients, typically for the purpose of surveillance of intracranial and spinal tumors (Hassepass et al., 2014; for a review, see Carlson, 2015).

Whereas the structural MRI is possible for patients with newer implants, the functional MRI cannot currently be carried out, mainly because the speech processor contains metal parts which are not compatible with MR scanners. Similarly, the MEG works by magnetism making acquisition of data from $\mathrm{CI}$ users hazardous, for CI users and scanners alike. The PET has been used in several studies with CI users, particularly for the study of neural plasticity (e.g., Lee et al., 2003; Naito et al., 2000; Strelnikov et al., 2010; Mortensen et al., 2006; Petersen et al., 2013). While PET provides excellent information of localization and lateralization, PET measurements are generally limited with respect to the spatial and temporal resolution and the invasiveness of the procedure, which requires the injection of radioactive ligands.

The EEG, in turn, is a non-invasive, silent and objective method which also enables one to record event-related brain potentials (ERPs). Hereby, the neural basis of perception and cognition can be investigated with a high temporal resolution. The ERPs do not reveal as accurate information as PET on the loci of the activated brain areas. They do, however, provide temporally precise information at the level of milliseconds on the various stages of information processing and the neural components associated with perception and behavior. Although the recording of EEG in CI users represents many challenges in data acquisition as well as in data analysis, it has proven to be a feasible and reliable method for the measurement of auditory functioning. The Mismatch Negativity (MMN) response in particular, has been proven a strong tool for measuring the capability of the auditory system.

\subsection{What is the MMN and what can be studied with the MMN?}

The MMN (Näätänen et al., 1978) is a component of the auditory event-related potential (ERP) recorded with electroencephalography (EEG) or magnetoencephalography (MEG). It has been related to the violation of expectancy in sound features such as phonemes, pitch, timbre, location of sound source, intensity, rhythm or to deviations in speech sounds or abstract auditory rules (Näätänen, 1992; Näätänen et al., 2001). The MMN peaks around 100-200 ms from violation onset (Fig. 1). The amplitudes and latencies of the MMN signal are related to the magnitude of deviation and to the perceptual discriminability, such that larger deviations yield MMN components with a larger amplitude and shorter peak latency (Näätänen and Picton, 1987). The amplitude and latency of the MMN correlate with auditory behavioral measures, for example with reaction time and hit rate in pitch discrimination tasks (Sams 
Table 1

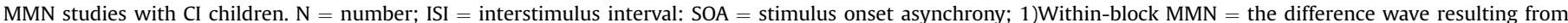

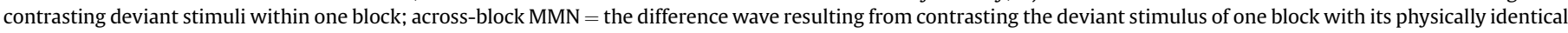

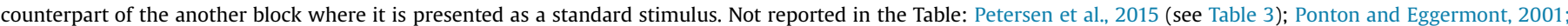
Titterington et al., 2003; Torppa et al., 2012 (see Table 3); Torppa et al., 2014b (See Table 3); Vavatzanidis et al., 2016.

\begin{tabular}{|c|c|c|c|c|c|c|c|}
\hline \multirow[t]{2}{*}{ Authors } & \multirow{2}{*}{$\begin{array}{l}\mathrm{N} \text { of } \mathrm{CI} \text { children } \\
\text { (uni/bilateral); } \\
\text { age; age at } \mathrm{CI}\end{array}$} & \multicolumn{2}{|l|}{ Stimuli for the MMN } & \multirow{2}{*}{$\begin{array}{l}\text { Duration of } \\
\text { std/deviant } \\
(\mathrm{ms}) ; \text { ISI (ms) }\end{array}$} & \multirow{2}{*}{$\begin{array}{l}\text { Total } \mathrm{N} \text { of } \\
\text { electrodes (those } \\
\text { used for MMN } \\
\text { analyses); Across/ } \\
\text { within-block }^{1}\end{array}$} & \multirow{2}{*}{$\begin{array}{l}\mathrm{CI} \text { Artifact } \\
\text { reduction } \\
\text { method }\end{array}$} & \multirow{2}{*}{$\begin{array}{l}\text { Other ERPs and } \\
\text { behavioral } \\
\text { methods }\end{array}$} \\
\hline & & Standard & Deviants & & & & \\
\hline Ponton and Don 1995 & $\begin{array}{l}4 \text { (unilateral); } \\
6 \text {-12 years } \\
\text { Age at CI not } \\
\text { reported }\end{array}$ & \multicolumn{2}{|c|}{$\begin{array}{l}\text { CI: Pitch: One electrode pair in } \\
\text { basal and one in apical region } \\
\text { was activated with biphasic } \\
\text { current pulses. Duration: } \mathrm{N} \\
\text { of electric pulses was altered. } \\
\mathrm{NH} \text { : Pitch and duration: } \\
\text { Altered acoustic clicks. }\end{array}$} & $\begin{array}{l}\text { Longest } \\
\text { stimulus20 } \\
\text { ms; ISI } 760\end{array}$ & $\begin{array}{l}30 \text { (subset of } 16 \\
\text { electrodes) } \\
\text { Visual inspection of } \\
\text { MMN) } \\
\text { Across-block }\end{array}$ & Not reported & \\
\hline Kileny et al., 1997a,b & $\begin{array}{l}14 \text { (unilateral); } \\
\text { 4-12 years; } \\
\text { ca. 3-9 years }\end{array}$ & $\begin{array}{l}\text { 1) } 1500 \mathrm{~Hz} \text { tone burst } \\
\text { presented at } 75 \mathrm{db} \\
\text { 2)"heed" (loudness roving) }\end{array}$ & $\begin{array}{l}\text { 1a) } 1500 \mathrm{~Hz} \text { tone } \\
\text { burst, } 90 \mathrm{db} \text {, } \\
\text { 1b) } 3000 \mathrm{~Hz} \text { tone } \\
\text { burst, } 80 \mathrm{~dB} \text {, } \\
\text { 2)"who'd" } \\
\text { (loudness roving) }\end{array}$ & $?$ & $\begin{array}{l}\text { ?; } \\
\text { Within-block }\end{array}$ & Not reported & $\begin{array}{l}\mathrm{N} 1, \mathrm{P} 2, \mathrm{~N} 2 \text {, and } \\
\mathrm{P} 3 . \text { Speech } \\
\text { recognition. } \\
\text { Language score? }\end{array}$ \\
\hline Ponton et al., 2000 & $\begin{array}{l}12 \text { (unilateral); } \\
6-18 \text { years; } \\
\text { identified up to } \\
5.1 \text { years }\end{array}$ & \multicolumn{2}{|c|}{ Same as in Ponton and Don (1995) } & $\begin{array}{l}\text { Longest } \\
\text { stimulus } \\
20 \mathrm{~ms} ; \\
\text { ISI } 760\end{array}$ & $\begin{array}{l}? ; \\
\text { Across-block }\end{array}$ & Not reported & \\
\hline Singh, 2004 & $\begin{array}{l}35 \text { (unilateral); } \\
7 \text { to } 17 \text { years; } \\
2-15 \text { years }\end{array}$ & Synthesized/ba/ & Synthesized/da/ & $\begin{array}{l}275 \\
\text { ISI } 1000\end{array}$ & $\begin{array}{l}21(\mathrm{Fz}, \mathrm{F} 3, \mathrm{~F} 4, \mathrm{C} 3 \\
\mathrm{C} 4) \\
\text { Across-block }\end{array}$ & $\begin{array}{l}\text { Described in } \\
\text { Singh, } 2004 \\
\text { (see Table N) }\end{array}$ & $\begin{array}{l}\text { P1, N1, P2, N2, } \\
\text { CAP, SIR }\end{array}$ \\
\hline Watson et al., 2007 & $\begin{array}{l}15 \text { (not reported); } \\
7-13 \text { years; } \\
2.7-6 \text { years }\end{array}$ & 500 or $2500 \mathrm{~Hz}$ tone bursts & $\begin{array}{l}500 \text { or } 2500 \mathrm{~Hz} \\
\text { tone bursts } \\
\text { (frequency as } \\
\text { standard in one } \\
\text { condition became } \\
\text { deviant in } \\
\text { the other } \\
\text { condition/ } \\
\text { vice versa) }\end{array}$ & $\begin{array}{l}50 ; \\
\text { ISI } 550\end{array}$ & $\begin{array}{l}5(\mathrm{C} 3, \mathrm{Cz}, \mathrm{C} 4, \mathrm{~T} 5, \mathrm{~T} 6) \\
\text { Across-block }\end{array}$ & Not reported. & $\begin{array}{l}\text { Digit Span tests } \\
\text { WISC-III } \\
\text { NWR Test } \\
\text { (repetition of } \\
\text { non-words of } \\
\text { increasing syllable } \\
\text { length). }\end{array}$ \\
\hline Ortmann et al., 2013 & $\begin{array}{l}18 \text { (unilateral); } \\
7-19 \text { years; } \\
<5 \text { years } \\
\text { (except one) }\end{array}$ & $\begin{array}{l}\text { The easiest pair (/bu/vs./ba/,/ } \\
\text { vs./bo/, bu/vs./pu/) was ident } \\
\text { for each CI user and used as } \\
\text { stimulus./bu/was standard ( } \mathrm{r} \\
\text { and deviant (run 2) }\end{array}$ & $\begin{array}{l}\text { /bu/ } \\
\text { tified } \\
\text { run 1) }\end{array}$ & $\begin{array}{l}420-451 \mathrm{~ms} \text {; } \\
\text { ISI } 900 \mathrm{~ms} \\
\text { (with jittering } \\
\text { of } \pm 200 \mathrm{~ms} \text { ) }\end{array}$ & $\begin{array}{l}32 \\
\text { MMN quantified/ } \\
\text { localized } \\
\text { with BESA (32). } \\
\text { Across-block MMN }\end{array}$ & $\begin{array}{l}\text { By subtracting } \\
\text { standard from } \\
\text { deviant }\end{array}$ & $\begin{array}{l}\text { Phoneme } \\
\text { discrimination }\end{array}$ \\
\hline Liang et al., 2014 & $\begin{array}{l}18 \text { (unilateral); } \\
1 \text { to } 6 \text { years; } \\
1.3-6.1 \text { years }\end{array}$ & Pure tone $1000 \mathrm{~Hz}$ & $\begin{array}{l}\text { Pure tone } \\
1500 \mathrm{~Hz}\end{array}$ & $\begin{array}{l}50 ; \\
\text { ISI } 900\end{array}$ & $\begin{array}{l}\text { 128; } \\
\text { Within-block }\end{array}$ & $\begin{array}{l}\text { Not reported/poor } \\
\text { channels amps } \\
\text { exceeding } 75 \mu \mathrm{V} \\
\text { excluded }\end{array}$ & $\begin{array}{l}\text { CAP } \\
\text { Children were } \\
\text { sedated }\end{array}$ \\
\hline $\begin{array}{l}\text { Vavatzanidis } \\
\text { et al., } 2015\end{array}$ & $\begin{array}{l}17 \text { (bilateral) } \\
11 \text { to } 45 \\
\text { months/right } \\
\text { after implantation }\end{array}$ & $\begin{array}{l}\text { /ba/with a short or with a lor } \\
\text { vowel ( } 202 \text { and } 341 \mathrm{~ms} \text {.). } \\
\text { Short syllable was standard } \\
\text { long syllable deviant/vice ve }\end{array}$ & & $\begin{array}{l}202 \text { and } 341 ; \\
\text { ISI } 855\end{array}$ & $\begin{array}{l}9(\mathrm{Fz}, \mathrm{Cz}, \mathrm{Pz}) \\
\text { Within-bock and } \\
\text { across-block }\end{array}$ & $\begin{array}{l}19 \text { children were } \\
\text { excluded due to } \\
\mathrm{CI} \text { artifact. }\end{array}$ & - \\
\hline
\end{tabular}

et al., 1985; Lang et al., 1995; Tiitinen et al., 1994; Novitski et al., 2004). Furthermore, the MMN is sensitive to discrimination learning (Näätänen et al., 1993) and hereby also to musical expertise (Tervaniemi, 2009).

The MMN provides an objective measure of auditory capabilities since it is pre-attentively elicited, requiring neither the subject's behavioral response nor attention towards the sounds (Näätänen et al., 1978; Alho, 1992; Paavilainen et al., 1993). Thereby, the MMN elicitation is free from confounding factors such as the familiarity with, and motivation in relation to performance in auditory tasks. Moreover, the MMN can be measured in individuals from whom it is difficult or even impossible to obtain reliable behavioral measures, for instance from aphasic (Csepe et al., 2001; Ilvonen et al., 2004) and comatose patients (Kane et al., 1993; Chausson et al., 2008), newborns (Partanen et al., 2013; Alho et al., 1990; Winkler et al., 2009), and fetuses (Cheour-Luhtanen et al., 1996; Draganova et al., 2005).

Hence, the MMN represents a potentially useful tool for an objective, clinical evaluation of auditory discrimination functions at the group level (Ponton et al., 2000). In individuals, however, the reliability of the MMN still has to be improved. Bishop and Hardiman (2010), found a significant MMN in $14(82 \%)$ of individuals, indicating that despite good behavioral discrimination, a few subjects show no MMN. For a review of the clinical applications of the MMN, see Duncan et al. (2009); Kujala et al., 2007; Näätänen, 2003; Näätänen and Escera, 2000; Csepe and Molnar, 1997). In the following, we will discuss how the MMN can be used for examining the auditory perception in $\mathrm{CI}$ users.

\subsection{Source localization}

One approach to study the source localization of ERP-responses from EEG-signal is distributed source analysis method (Beamformer, Loreta, sLoreta and Minimum-Norm Estimates(MNE)). Another approach is discrete source analysis (dipole modeling). In CI users, several EEG source localization approaches have been used (e. g., dipole modeling, Debener et al., 2008; Sandmann et al., 2009; Linear Beamforming, Senkowski et al., 2014; sLORETA, Schierholz 
A) Mismatch Negativity (MMN)

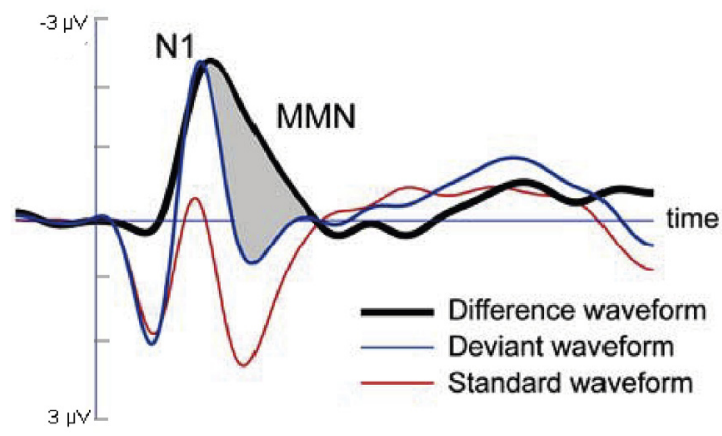

B)

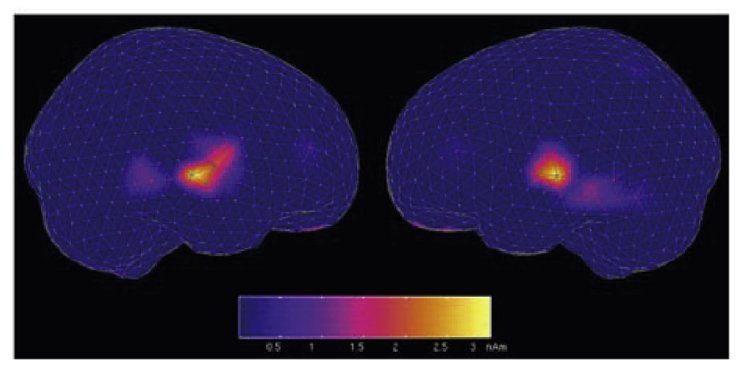

Fig. 1. Schematic illustration of the mismatch negativity (MMN). A) ERP waveforms evoked at a frontal scalp location by the standard and deviant sounds superimposed on the difference waveform in which the ERP to the standard has been subtracted from that to the deviant. The MMN appears as an enlarged negativity to the deviant sound as compared with the standard sound, following the N1 peak. B) Illustration of the supratemporal bilateral sources in the left and right hemispheres of the MMN response to the deviant sound. Modified from Tervaniemi and Brattico (2004). The figure is from Professor Elvira Brattico's academic dissertation (2006). Reprinted with permission of the author.

et al., 2017; L2-MNE, Ortmann et al., 2013, 2017). It is not yet clear which method is the best one even for NH subjects. Evidently, it would be beneficial to compare the results from different approaches (Mahjoory et al., 2017).

For source modeling of the brain responses of young children, individual head models are essential to get reliable results. The reason for this is that the brain and its surrounding structures undergo large anatomical and histological changes in childhood, the time course of these changes evidently differing between individuals. These changes lead to changes in electrophysiological activity (see for example, Ortiz-Mantilla et al., 2012). Unfortunately, in $\mathrm{CI}$ children, individual head models cannot be acquired because magnetic resonance imaging (MRI) is not possible for them. Future studies should address this problem.

\section{MMN, speech perception and language development in $\mathrm{CI}$ users}

Objective, non-behavioral measures of auditory discrimination such as the MMN remain a potentially powerful, but as yet underutilized, application for this patient population (Ponton et al., 2000). Thus, in the following, we will propose that the MMN can be used as a viable and objective measure for auditory capabilities, progress and training efficiency in $\mathrm{CI}$ recipients. In particular, we will review the potential of the MMN as an instrument for assessing the functioning of the $\mathrm{CI}$, for monitoring the gradual improvement of auditory discrimination after the $\mathrm{CI}$ switch-on, for evaluating the effectiveness of different training programs and rehabilitation, for assessing the preserved memory traces during the period of deafness preceding the $\mathrm{CI}$ installation, and for evaluating the performance of $\mathrm{CI}$ users in the perception of music, in both adults and children. Finally, we will give an overview of the practical issues in MMN recording and analysis in $\mathrm{CI}$ recipients.

\subsection{Pioneering studies}

The pioneering MMN recordings from CI users conducted by Kraus et al. (1993) employed syllable contrasts (standard/da/vs. deviant/ta/) as their stimuli. They showed that the MMN elicited in CI users was remarkably similar to the MMN obtained from a group of age-matched $\mathrm{NH}$ control subjects. Thus, despite the major differences in the peripheral input, the brain of the $\mathrm{CI}$ users seemed to process basic speech units in a fashion very similar to that of $\mathrm{NH}$ controls, leading to the conclusion that the MMN shows promise as a measure for the objective evaluation of the cochlear implant function, and for the study of central neurophysiological processes underlying speech perception. Consistent with this, Ponton et al., (2000; see also Ponton and Don, 1995, 2004) found that the MMNs for contrasts in simple stimulus duration delivered directly to the $\mathrm{CI}$ electrodes were rather similar for CI-users and agematched $\mathrm{NH}$ adults.

In a detailed investigation, Groenen et al. (1996) reported that whereas the individuals classified as good CI performers (based on behavioral speech-perception measurements) disclosed an MMN, the poor performers failed in generating a comparable response. The authors concluded that there seems to be a relation between speech perception ability and the quality of the MMN signal. Furthermore, the authors advocated for a refinement of the MMN paradigms for studying the different aspects of auditory processing to fundamentally understand the effects of electrical stimulation of the inner ear and to clinically adjust rehabilitation (Groenen et al., 1996, p. 112).

\subsection{MMN development in adults with CIs}

The improvement of vowel discrimination in the early postimplant period was investigated in the afore mentioned study by Kraus et al. (1993). Subsequently, tracking the changes in language function in a group of deaf adults after receiving their CIs, Lonka et al. $(2004,2013)$ found that while the MMN was absent for approximately 12 months post-surgery, the MMN response subsequently emerged first for a large vowel contrast, and then later for a more subtle vowel distinction. A converging behavioral performance improvement was also observed during the follow-up period. According to Lonka and her colleagues, their results suggested that plastic changes occurred in the auditory cortex of these patients while the discrimination of the speech sounds improved (Fig. 2). Importantly, one of these changes might be the reactivation of cortical phoneme traces (Näätänen et al., 1997) that were formed before the period of deafness.

In line with these findings, in the light of the results obtained by Salo et al. (2002), it seems plausible that the neural memory traces once developed for the mother tongue speech sounds remain quite stable even in a total deprivation from supportive stimulation. These authors studied the MMN responses to the frequency changes of the second formant (F2) of the Finnish/i/in CI listeners. The participants also completed a task where they were asked to adjust the F1 and F2 parameters of a vowel synthesizer to produce Finnish vowels. It was found that the $\mathrm{CI}$ subjects exaggerated the contrasts between the vowel categories and further, that an MMN could be identified from that patient who adjusted the F1 and F2 parameters closest to the prototypical Finnish vowels, suggesting that the memory traces for the vowels had remained stable during the period of deafness. 

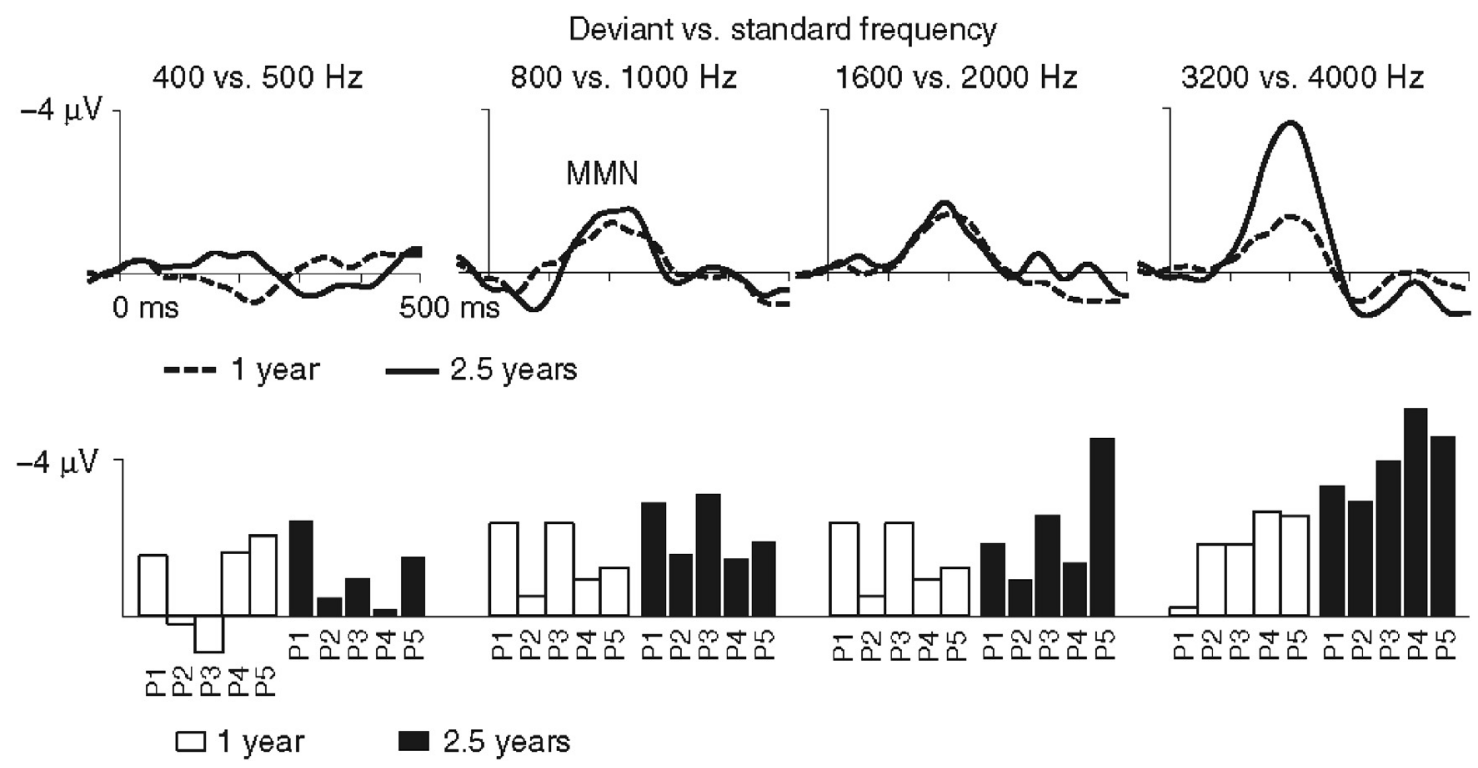

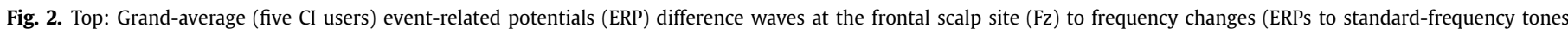

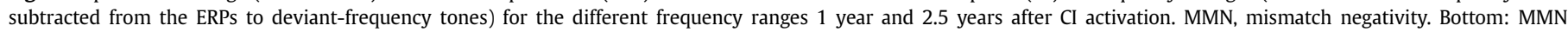

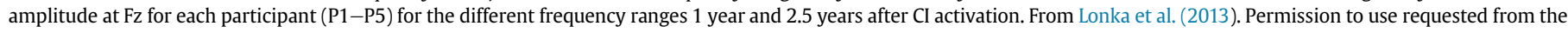
publisher.

The stability of these memory traces probably explains the fact that the post-lingually deafened patients benefit from the $\mathrm{CI}$ soon after the implantation. The information delivered through the $\mathrm{CI}$ seems to activate neural phonetic memory traces underlying the generation of the MMN. Consistent with this, Perkel et al., 1992 who studied the speech of post-lingually deafened patients before and after the activation of the CI suggested that gains in production may be governed at least as much by prior linguistic experience as by perceptual gains. However, some higher aspects of linguistic processing such as that of syntax may be affected even in proficient $\mathrm{CI}$ users (Hahne et al., 2012).

\subsection{Auditory development in children with CIs indexed by the MMN}

The first results on the development of the MMN of CI children were reported by Ponton et al. (2000). The age of the children ranged from five to 20 years and the age at implantation was fairly high, with the average age at the detection of deafness being one to two years and the average period of deafness being 3,5 years (Ponton and Eggermont, 2001). The aim was to study whether the MMN can be used to assess the extent to which a $\mathrm{CI}$ provides discriminable information to the user. This would be extremely useful, especially for young implanted children who still have restricted language skills. The MMNs were evoked by a duration difference in a click train (for NH children) or in a pulse train (for $\mathrm{CI}$ children), with the stimulus being monaural. It was found that an MMN was present in a group of implanted children who have good spoken language perception through their CI. Furthermore, the authors found differences in the MMN scalp distribution between the $\mathrm{CI}$ and $\mathrm{NH}$ children. The MMN amplitude was more symmetrical over both hemispheres in $\mathrm{CI}$ children whereas it was initially much larger over the contralateral hemisphere in $\mathrm{NH}$ children. These findings suggest that, compared to, for example, obligatory responses like $\mathrm{N} 1$, the MMN is a better measure of basic auditory processes necessary for the development of spoken language perception skills in profoundly deaf children listening with the aid of a CI.

Liang et al. (2014) conducted a longitudinal study of the auditory-cortex functional development using the MMN. Their participants were one to six years old, pre-lingually severely-toprofoundly hearing-impaired children. Recordings were conducted in sedation at different time points from one to six months postoperation. The standard stimulus was a pure tone of $1000 \mathrm{~Hz}$ while the deviant stimulus was a pure tone of $1500 \mathrm{~Hz}$, presented in free field. It was found that the individual MMN incidence gradually increased during the follow-up period. Moreover, the MMN peak latency decrement from Month 3 to Month 6 correlated significantly with the increment of the CAP scores (with the CAP assessing auditory ability development in children; Archbold et al., 1995).

The authors concluded that "MMN incidence increment and latency decrement are likely to be the objective and noninvasive indicators for evaluating auditory central development at the early stage in children after CI power-up" (p. 13). Moreover, they pointed out that the MMN peak-latency decrement from Month 3 to Month 6 that correlated significantly with the increment in the CAP scores indicated a fast maturation period, which might be a key period for auditory rehabilitation.

In their study on music perception in children with a CI, Torppa et al. (2012) inspected the maturation of MMN responses in CI children aged from four to 13 years, who already had long-term experience in hearing with a $\mathrm{CI}$ (see Table 1). The $\mathrm{CI}$ children were divided in repeated measures analysis of variance to two age groups (children younger/older than six years and nine months). Results indicated a non-significant tendency to a longer latency of the MMN in younger children for the gap of $40 \mathrm{~ms}$ and to larger MMN amplitudes in older children to changes in $\mathrm{f}_{0}$. The MMN amplitude for change from piano tone to cymbal tone was significantly larger in older compared to younger children (Fig. 3). The results indicated that the maturation of MMN by age was similar for the $\mathrm{CI}$ and $\mathrm{NH}$ control children.

An important aspect of children's perception of speech is the perception of word stress and their patterns which convey information about word boundaries in rhythmic languages like German, English, French, Hebrew (for a review, Vavatzanidis et al., 2016) and Finnish (word stress perception in Finnish CI children, see Torppa et al., 2014a). Using this cue, young children are able to derive 


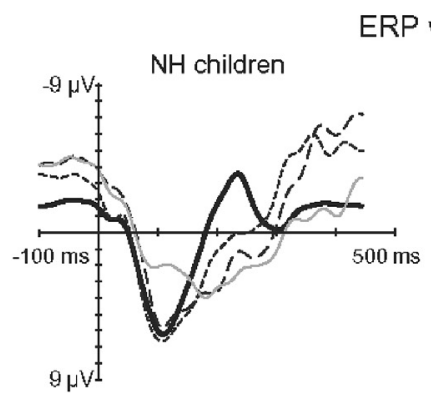

Baseline $-100 \mathrm{~ms}-350 \mathrm{~ms}$

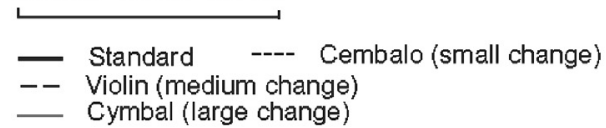

Cl children

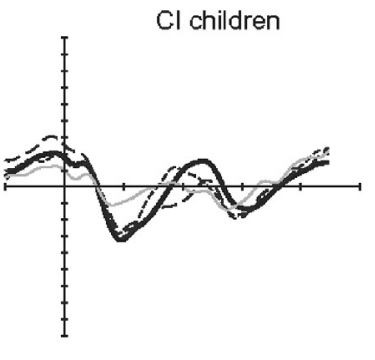

1

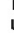
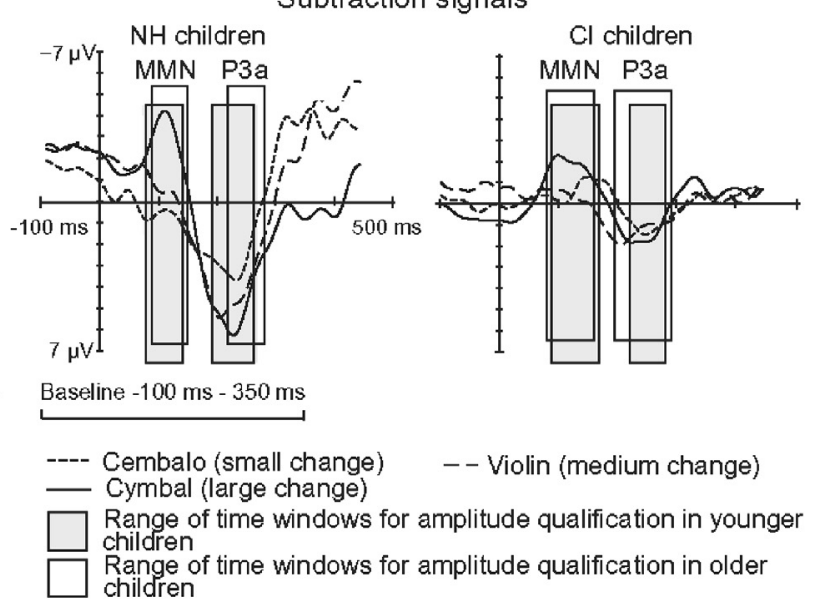

aseline $-100 \mathrm{~ms}-350 \mathrm{~ms}$

Cembalo (small change)

Cymbal (large change)

children

children

Subtraction signals

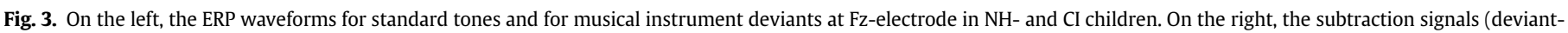
standard) showing MMN and P3a respectively. From Torppa et al. (2012). Permission to use requested from the publisher.

and learn new words from continuous speech. The acoustic cues for word stress are changes in pitch $\left(f_{0}\right)$, intensity and duration (for a review, Torppa et al., 2014a).

Vavatzanidis et al. (2015) followed the development of the MMN for vowel duration (length) right after the implantation in young $\mathrm{CI}$ children (age at $\mathrm{CI}$ activation from 11 to 45 months) and in the $\mathrm{NH}$ control group. In their MMN paradigm,/ba/was presented either with a short or with lengthened vowel. In one of two stimulus blocks, the short syllable was the standard and the long syllable the deviant and vice versa, and correspondingly, they measured the socalled within-block and across-block MMNs (see Section 5.1). They conducted six measurements, one preoperatively and five during the first eight months of implant use. Only two months after the first auditory input, these early-implanted children differentiated between the long and short syllables. Further, the $\mathrm{CI}$ children reached MMN amplitude values similar to those of the NH group only four months after their first auditory experience. The authors stated that "this is remarkable, considering that being congenitally deaf they are lagging behind at least 1 year from their $\mathrm{NH}$ age peers in terms of hearing experience." (p. 2437).

Vavatzanidis et al. (2016) followed the development of the MMN for changes in syllable stress patterns in CI children (age at first activation of the $\mathrm{CI}, 9-50$ months) during first six months after $\mathrm{CI}$ activation and in the $\mathrm{NH}$ control group. In one of the two stimulus blocks, the trochaic pattern (the first syllable stressed, e. g.,/ba:ba/) was the standard stimulus and the iambic pattern (the second syllable stressed, e. g.,/baba:/) the deviant stimulus or vice versa. The stress pattern was cued with changes in duration, but also with changes in intensity and the 1st-4th formants (as exact changes in pitch or $f_{0}$ are not reported).

Vavatzanidis and colleagues found that the ERP curves of the implanted children were very similar to those of their NH peers. The negative, MMN-like response to the iambic stimulus was visible at two months and significant at four months after the $\mathrm{CI}$ activation (for the subgroup of congenitally deaf children after 6 months of $\mathrm{CI}$ use). In all child groups, an MMN-like mismatch response was present for the iambic deviant, but not for the trochaic stimulus typical for the native language of the participants. Vavatzanidis and colleagues stated that this is consistent with the findings of Friederici et al. (2007) showing that NH infants strongly respond to the non-native stress pattern but not to the native stress patterns. According to the authors, their results demonstrate that the $\mathrm{CI}$ allows the differentiation between native and foreign stress patterns and thus transmits word stress cues for language acquisition.

\subsection{MMN as an indicator for good vs. poor CI speech performance}

In their long-term assessment of patients with CIs using the MMN, Singh (2004) observed that initially, there were MMN responses in $80-85 \%$ of good performers in speech perception but only in $15-20 \%$ of poor performers. Reassessing after two years, $50 \%$ of the poor performers, in whom MMNs were elicited, had become good performers, whereas only $25 \%$ of poor performers with no MMN became good performers. The authors concluded that presence of an MMN could be a good indicator for evaluating the cortical status after cochlear implantation.

Consistent with this, a recent study by Turgeon (2014) investigated MMN responses elicited by speech-sound contrasts. In their paradigm, the standard stimulus was/da/, while the deviant stimuli were syllables/ba/and/ga/. The authors reported that in the good performers, the MMN in fact resembled in amplitude that of the normal healthy control subjects. Moreover, a bivariate binomial correlation analysis showed a positive correlation between the MMN amplitude and the speech-recognition score. The authors concluded that the MMN can distinguish between $\mathrm{CI}$ users who have good versus poor speech-recognition ability as assessed with conventional tasks. Furthermore, they suggested that the MMN can be used to assess speech-recognition proficiency even in CI users who cannot be tested with regular speech-recognition tasks, e.g., in infants and other non-verbal populations, raising the possibility that the MMN could be used "to evaluate speech recognition and to assess improvement following implantation and intervention in infants and non-verbal adults" (p. 834). Consequently, these results indicate that the clinical use of the MMN is "feasible and informative" (p. 832).

This conclusion is also supported by the results of Kelly (2005). These authors observed that the MMN for tone-frequency change was absent or degraded in CI patients with poor speech scores. It was concluded by the authors that the MMN is a useful tool for objectively assessing auditory discrimination in patients with CIs.

In addition, Kelly, 2005 reported a similar failure to record an MMN from CI users defined as poor performers on the basis of their speech scores. Moreover, Zhang, 2011 found that good CI performers displayed MMNs with a large peak amplitude whereas moderate-to-poor performers showed small or absent MMNs. An 
analogical data pattern can also be observed in children with CIs. It was found by Kileny et al. (1997a,b) that in children with CIs between the ages of four and twelve years, the MMN and P3 amplitudes for a tone-frequency change correlated significantly with the results of tests evaluating speech-recognition skills. These two tests were The Glendonald Auditory Speech Perception (GASP), assessing the child's ability to identify familiar words and sentences in an open-set format, and The Word Intelligibility by Picture Identification Test (WIPI) which assesses the identification of one-syllable words in a closed set of 6 words.

The authors concluded that the clinical use of cognitive evoked potentials in children with CIs is feasible and informative. Further, "given the strong relationship between some of the measures of cognitive evoked potentials and traditional speech recognition scores, this procedure holds promise as a clinically useful technique for evaluating young children with cochlear implants. In particular, this measurement allows us to evaluate central auditory processing skills of young children in whom behavioral measurement may be difficult or unreliable. In addition, this technique has the potential of providing insight into auditory learning and auditory memory in this patient population." (Kileny et al., 1997a,b, p. 168). See also Watson et al. (2007).

Importantly, Ortmann et al. (2013) aimed at determining the central factors accounting for developing satisfactory speech performance in children and adolescents with prelingual hearing loss. In their study, two groups of CI users, one with "very good" and the other with "very bad" speech performance, were matched according to the hearing age and the age at implantation. It was assessed whether these two CI groups differed from each other with regard to their phoneme-discrimination ability and auditory sensory-memory capacity. These functions were measured behaviorally and by using the MMN. It was found, that the behaviorally measured phoneme-discrimination ability was comparable in the group of good CI-performers and matched healthy control participants, which were both better than that of the bad performers. Further, source analyses revealed a larger MMN activity (at 155-225 ms) in good compared with bad performers, which was generated in the frontal cortex and positively correlated with behavioral measures of working memory. These results indicate, according to the authors, that the two CI groups developed different auditory speech-processing strategies and emphasize the role of phonological functions of auditory sensory memory and the prefrontal cortex in positively developing speech perception and production.

Kraus et al. (1993) proposed that the MMN could provide a neurophysiologic basis for the design of $\mathrm{CI}$ rehabilitation programs, since it is an effective neurophysiological index of fine acoustic stimulus processing. To assess this aspect, Trautwein et al. (1998) and Ponton et al. (2000) who assessed patients with CI by using non-speech stimuli, obtained results that relate back to both speech performance and training. Trautwein et al. (1998) found that while the psychophysical thresholds were superior to the MMNestimated discrimination thresholds for duration contrasts in the control group, the opposite held true for the group of adult CI users. Thus, in a number of patients, there was neurophysiological evidence for discrimination based on the MMN, without the patient being able to behaviorally discriminate the difference. Based on the apparent separation of discrimination at the level of sensation versus perception, Ponton et al. (2000) developed a protocol based on pre-training MMN evaluation to determine whether there was neurophysiological evidence for discrimination in the absence of perceptual discrimination. This knowledge was then used to develop a training protocol which resulted in significant improvements in frequency discrimination as well as in combined consonant and vowel discrimination in a single profoundly trained adult
CI user. Important background information for this kind of developmental work was very recently provided by Moberly, 2016 MMN study on acoustic cue weighing in adults with CIs.

\section{MMN in clinical testing and training - refinement of the methodology}

As noted by Roman et al. (2005a), there is a clear application of the MMN in clinical testing and training of $\mathrm{CI}$ populations. However, refinements are needed in methods and recording technique to optimize protocols for these purposes. These authors studied postlingually implanted adult patients and found that frequencydiscrimination ability (between tones of 1000 and $1500 \mathrm{~Hz}$ ) could be demonstrated in all but one of their patients with $\mathrm{CI}$. An interesting, and commendable, methodological aspect of their investigation was to average the MMN from 8 fronto-central electrodes, covering the scalp area with the highest MMN amplitudes, which revealed, according to the authors, the MMN more precisely (see also section NN "Electrodes used for recording and quantification of MMNs" in the end of the present review).

\subsection{MMN in individual CI users}

The MMN is typically recorded at the group level. This is not optimal for clinical purposes, where it is essential to judge and follow the auditory capacity of individuals. Consistent with this, many studies, especially the pioneering ones, have looked at the MMN in individual CI listeners (Tables 1 and 2).

In the study by Kraus et al. (1993), the latency was determined for the onset, offset, and peak (the point of the maximum negativity) of the MMN for syllable contrasts (standard/da/vs. deviant/ $\mathrm{ta} /$ ), using the grand average difference waveforms from individual subjects. T-tests were performed on the deviant/ta/(in oddball paradigm) and deviant minus/ta/-alone difference waveforms comparing the amplitudes at these same three latency points. An MMN was considered to be present for an individual if the amplitude of the peak was significantly different from the onset or offset amplitudes of the MMN in both the deviant minus standard and deviant minus/ta/-alone conditions.

Ponton et al. (2000) developed a statistic named the "MMNi", or the MMN-integrated, in which the averaged evoked potentials for the standard and deviant stimuli are integrated and compared with the individual's own variability for the standard stimulus across randomized, multiple trials. Based on their findings, Ponton et al. (2000) promoted using the MMNi as a clinical tool for examining individual differences in speech perception, short-term auditory memory, and speech-discrimination skills (for a review, see Johnson, 2009).

Singh, 2004 identified MMN (standard/ba/, deviant/da/, synthesized stimuli) from difference waves of individual CI subjects. The MMN was the visually identified negativity deflecting from the baseline in the difference waveform between approximately 100 and $350 \mathrm{~ms}$ from stimulus onset. The reproducibility of the MMN was assessed by comparing averages constructed from equal numbers of random epochs, and odd and even averages were extracted from the complete data sets. If the MMN identified in the difference waveform was not reproducibly present in the subaverages in any of the above-described averages, then it was not regarded as a true MMN. The parameters from the Fz electrode site were used for all statistical analyses. The results indicated that an MMN was much more likely present in patients who had better behavioral performance scores, namely in the Categories of Auditory Performance (CAP) and Speech Intelligibility Rating (SIR). The authors concluded that the presence of an MMN in these patients may serve as a valuable positive prognostic marker indicating 
Table 2

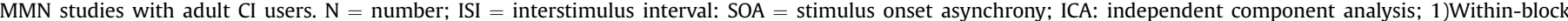

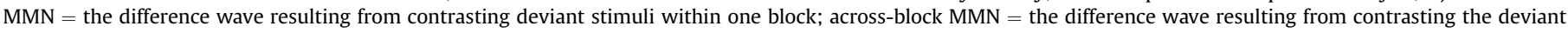
stimulus of one block with its physically identical counterpart of the another block where it is presented as a standard stimulus.

\begin{tabular}{|c|c|c|c|c|c|c|c|}
\hline \multirow[t]{2}{*}{ Authors } & \multirow{2}{*}{$\begin{array}{l}\mathrm{N} \text { of } \mathrm{CI} \text { users } \\
\text { (uni/bilateral); } \\
\text { age; age at } \\
\mathrm{CI} / \text { strategy }\end{array}$} & \multicolumn{2}{|l|}{$\begin{array}{l}\text { Stimuli for } \\
\text { the MMN }\end{array}$} & \multirow{2}{*}{$\begin{array}{l}\text { Duration of } \\
\text { std/deviant } \\
(\mathrm{ms}) / \text { ISI or SOA }\end{array}$} & \multirow{2}{*}{$\begin{array}{l}\text { Total } \mathrm{N} \text { of electrodes } \\
\text { (those used for MMN } \\
\text { analyses); } \\
\text { Across/within-block }^{1}\end{array}$} & \multirow{2}{*}{$\begin{array}{l}\text { CI Artifact } \\
\text { reduction } \\
\text { method }\end{array}$} & \multirow[t]{2}{*}{$\begin{array}{l}\text { Other ERPs and } \\
\text { behavioral methods }\end{array}$} \\
\hline & & Standard & Deviants & & & & \\
\hline Kraus et al., 1993 & $8 /$ not reported & /da/ & $|\mathrm{ta}|$ & 100; ISI 1000 & $\begin{array}{l}2(\mathrm{Fz}) \text {; Within and } \\
\text { across-block }\end{array}$ & Not reported & $\begin{array}{l}\text { Monosyllable words } \\
\text { subjective satisfaction }\end{array}$ \\
\hline Groenen et al., 1996 & 7/MPeak & /ba/ & /da/ & 175 & & & Antwerp-Nijmegen test battery \\
\hline Salo et al., 2002 & $\begin{array}{l}4 \\
22 \text { Nucleus }\end{array}$ & $\begin{array}{l}/ \mathrm{i} /, \mathrm{F} 2 \\
2230 \mathrm{~Hz}\end{array}$ & $\begin{array}{l}\text { F2 } \\
\text { D1 } 2313 \mathrm{~Hz} \\
\text { D2 } 2400 \mathrm{~Hz} \\
\text { D3 } 2488 \mathrm{~Hz} \\
\text { D4 } 2578 . \mathrm{Hz}\end{array}$ & 500; SOA 850 & 20 (Fz); Within-block & Not reported & $\begin{array}{l}\text { Word recognition scores } \\
\text { Speech reception thresholds } \\
\text { Speech production analyses }\end{array}$ \\
\hline Lonka et al., 2004 & $\begin{array}{l}5 \\
\text { SPEAK }\end{array}$ & $|e|$ & $\begin{array}{l}\mathrm{D} 1 / \varnothing / \\
\mathrm{D} 2 / \mathrm{o} /\end{array}$ & $\begin{array}{l}400 ; \\
\text { SOA } 900\end{array}$ & & & Finnish bisyllabic words \\
\hline Roman et al., 2005a,b & $\begin{array}{l}7 \\
\text { SPEAK }\end{array}$ & $1 \mathrm{kHz}$ & $\begin{array}{l}\text { D1 } 2 \mathrm{kHz} \\
\text { D2 } 1.5 \mathrm{kHz}\end{array}$ & 30; ISI 1030 & $\begin{array}{l}32 \text { or } 64(\mathrm{~F} 3, \mathrm{Fz}, \mathrm{F} 4, \mathrm{FC} 1 \text {, } \\
\mathrm{FC} 2, \mathrm{C} 3, \mathrm{C} 4, \mathrm{Cz}) \text {; Within } \\
\text { and across-block }\end{array}$ & Not reported & $\begin{array}{l}\mathrm{N} 1-\mathrm{P} 2 \\
\text { Pure tone audiogram } \\
\text { Word discrimination }\end{array}$ \\
\hline Kelly, 2005 & $\begin{array}{l}12 \\
\text { SPEAK }\end{array}$ & $1 \mathrm{kHz}$ & $\begin{array}{l}\text { D1 } 1.5 \mathrm{kHz} \\
\text { D2 } 1.25 \mathrm{kHz}\end{array}$ & 60; ISI 600 & $\begin{array}{l}3(\mathrm{Fz}, \mathrm{Cz}, \mathrm{Pz}) \\
\text { Within-block }\end{array}$ & Not reported & $\begin{array}{l}\text { MLR, CAEP, P3 } \\
\text { Word tests } \\
\text { Sentence test }\end{array}$ \\
\hline Zhang, 2011 & $\begin{array}{l}5 \text { good } \\
5 \text { mod-bad } \\
\text { ACE }\end{array}$ & $1 \mathrm{kHz}$ & $2 \mathrm{kHz}$ & $\begin{array}{l}60 ; \\
\text { ISI } 700\end{array}$ & $\begin{array}{l}40 \text { (F3, Fz, F4, C3, Cz, } \\
\text { C4, FC3, FCz, FC4); } \\
\text { Within and across-block }\end{array}$ & ICA & $\mathrm{N} 1-\mathrm{P} 2$ \\
\hline Obuchi et al., 2012 & $\begin{array}{l}3 \\
\mathrm{ACE}\end{array}$ & $1 \mathrm{kHz}$ & 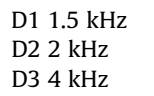 & $\begin{array}{l}\text { Rate } 1 \text { per } \\
\text { second }\end{array}$ & 3 (?); Within-block & Not reported & $\begin{array}{l}\text { P300 } \\
\text { Japanese Speech } \\
\text { Intelligibility test }\end{array}$ \\
\hline Lonka et al., 2013 & $\begin{array}{l}5 \\
\text { SPEAK }\end{array}$ & $\begin{array}{l}\text { S1: } 500 \mathrm{~Hz} \\
\text { S2: } 1000 \mathrm{~Hz} \\
\text { S3: } 2000 \mathrm{~Hz} \\
\text { S4: } 4000 \mathrm{HZ}\end{array}$ & $\begin{array}{l}\text { D1: } 400 \\
\text { D2: } 800 \\
\text { D3: } 1600 \\
\text { D4: } 3200\end{array}$ & $\begin{array}{l}100 \\
\text { SOA } 600\end{array}$ & $\begin{array}{l}2(\mathrm{Fz}) ; \\
\text { Within-block }\end{array}$ & Not reported & Finnish bisyllabic words \\
\hline Turgeon, 2014 & $\begin{array}{l}20 \\
\text { not reported }\end{array}$ & /da/ & $\begin{array}{l}\text { D1/ba/ } \\
\text { D2/ga/ }\end{array}$ & $\begin{array}{l}225 ; \\
\text { ISI } 1000\end{array}$ & $\begin{array}{l}128(\mathrm{AFz}, \mathrm{Fz} \text {, and } \mathrm{FCz}) \\
\text { Within-block }\end{array}$ & ICA & French word lists \\
\hline
\end{tabular}

favorable prognosis in the long run. However, a large percentage of these $\mathrm{CI}$ listeners did not disclose an MMN. Therefore, according to the authors, an absent MMN should be interpreted with caution, since a poor signal-to-noise ratio for reasons such as a too short duration of recording may be the reason why a MMN is not evident in some patients.

A rather similar method for identifying individual MMN responses has been used by Zhang et al. (2013a) who tested the melodic interval contour identification behaviorally and neurally using MMN responses. The 'standard' stimuli were the rising and falling contours with 1 - or 5-semitone spacing. The 'deviant' stimuli were the rising-flat and falling-flat contours with 1- or 5-semitone spacing. An MMN was a visually identified negativity deflecting from the baseline in the difference waveform between approximately 100 and $350 \mathrm{~ms}$ from stimulus onset. To further judge the presence of the MMN, a point-by-point $t$-test of the two averaged waveforms (standard and deviant) was performed over the latency range where the MMN was visually identified. The MMN was regarded as being valid if the two waveforms were significantly different from each other. It was found that an MMN was present in individual CI subjects only in the easier condition where the contours had a five-semitone spacing.

Previously, a methodologically interesting contribution was also provided by Wable et al. (2000) who analyzed the MMN in CI patients to assess electrode discrimination in these patients, following the example given by Ponton and Don (1995). The latter authors compared MMN responses in an electrode-pair stimulation paradigm of patients with $\mathrm{CI}$ to tone-burst stimulation in $\mathrm{NH}$ controls and found MMN responses with shorter peak latencies with electrical stimulation which may be explained, according to the authors, by a more synchronized activation of neurons in the case of electrical stimulation. Consistent with this, Wable and associates found that an MMN can be elicited when stimulating two different $\mathrm{CI}$ electrodes, with one for the standard stimuli and the other for the deviant stimuli.

In line with this, Nager et al. (2007) found that adult CI users are impaired in the pre-attentive registration, indexed by a greatly attenuated P3a response to novel sounds in the passive oddball condition, an index of automatic orienting of attention. In contrast, in the active condition, the patients and controls did not differ from one another with regard to hit rates and RTs. Furthermore, the ERPs elicited by novel stimuli were characterized by enhanced N2b and P3b components that did not differ in amplitude between the two groups. The authors concluded that the finding involving the clearly diminished P3a response is of note because it provides the first direct evidence demonstrating that auditory novel events outside the attentional focus fail to automatically capture attention in cochlear implantees, which may make it more challenging for these patients to navigate in environments that rely on the ability to reorient the attentional focus when encountering unexpected sounds (Nager et al., 2007, p. 395). This might e.g. have important, unless fatal, implications to traffic safety (see Näätänen and Summala 1982).

\section{MMN in relation to music perception in CI recipients}

While the first aim of the $\mathrm{CI}$ rehabilitation was just to allow the perception of speech, developing the perception of music has recently become an important aim of $\mathrm{CI}$ development and rehabilitation. This need may have partially arisen from the increasing amount of scientific evidence for the positive impact of one's favorite music in humans (for example, arousal: Carr and Rickard, 2015; pleasure and award: Zatorre and Salimpoor, 2013), from a growing body of evidence on the common processing between 
music and speech perception, and from results suggesting that speech perception and underlying aspects (like pitch and duration perception, attention and memory) can be rehabilitated with musical activities or training (Besson et al., 2011; Strait et al., 2012; Patel, 2014). The many MMN studies on the neural basis of music is one outcome of these developments.

\subsection{Results from odd-ball paradigms -neural responses for changes in musical syntax, timbre, attack time and melodic contour}

Koelsch et al. (2004), in a pioneering study, found that the MMN and P3a elicited by timbre deviants (e. g., chords played with piano vs. trumpet or organ) were present in adult CI recipients. Moreover, music-syntactic violations in chord sequences elicited an early right anterior negativity (ERAN) which had amplitude and latency similar to the MMN but more frontally located sources (Garza Villarreal et al., 2011; Leino et al., 2007). All these responses were considerably smaller in amplitude in CI-recipients than those elicited in controls, indicating, according to the authors, that the amount of sensory information received through a $\mathrm{CI}$ is smaller compared to an intact natural cochlea. Nevertheless, this demonstrated that the neural mechanisms for detecting irregularities in physical (timbral) and syntactic changes in music are activated even through the $\mathrm{CI}$.

Consistent with the findings from Koelsch et al. (2004), Zhang et al. (2013b) reported that the MMN for changes in musical instruments (timbre) was elicited in all adult control-group individuals but only in approximately half of the adult CI-recipients studied. Moreover, in those CI-users that displayed MMN responses, the MMN peak amplitude was smaller and duration shorter than those of the NH controls. As Zhang et al. (2013b) point out, the results of the timbre MMN are consistent with behavioral results showing poorer timbre perception in CI-recipients compared to that of $\mathrm{NH}$-listeners. Hence, the MMN can provide an objective tool not only in studying the neural coding of timbre but also in the future efforts of improving $\mathrm{CI}$ design and speech strategy.

Temporal and feature perception in relation to musical timbre perception in post-lingually deafened CI users was studied by Timm et al. (2012). They manipulated the first $60 \mathrm{~ms}$ of a cornet sound in order to determine whether these differences in the temporal envelope of the sounds, in particular the attack time, are detected by CI-users. Timm and her colleagues found that the MMN was elicited in the $\mathrm{NH}$ control participants only. Consequently, the authors concluded that small differences in temporal envelope are difficult to perceive for $\mathrm{CI}$ users and that further research is needed to determine the minimal and maximal borders of this altered perception. Moreover, the authors encouraged musical training in CI users since it has been shown to strongly affect ERPs, in particular the MMN, an index of sound discrimination (see Tervaniemi et al., 1997).

Quite recently, Zhang et al. (2013a) used the MMN to compare the ability of $\mathrm{CI}$ and $\mathrm{NH}$ adults to neurally and behaviorally detect the changes in melodic contours, presented with complex tones $\left(\mathrm{f}_{0}\right.$ and two harmonics). Several EEG oddball paradigms were presented to the participants, with the pitch interval between the tones in melodies being either one or five semitones. The MMN was present for $\mathrm{CI}$ recipients with the 5-semitone spacing but not when the interval was only one semitone. Even though the MMN durations, amplitudes and latencies (with five semitone spacing) were diminished in $\mathrm{CI}$ recipients compared to those in the $\mathrm{NH}$ subjects, the differences between groups were not statistically significant even though these results were in line with the findings from behavioral assessments.

According to the authors, the results suggest that larger changes in pitch (five semitones) may be sufficiently perceived by some CI users, despite of the degraded input from CIs. The authors also list other confounding factors such as less recruitment of the auditory cortex in $\mathrm{CI}$ subjects than in $\mathrm{NH}$ listeners when processing sounds due to the period of deafness, and deficiencies in working memory and auditory attention in $\mathrm{CI}$ recipients. Further, they propose that the MMN may be used: "(1) to assess neurophysiological processing of pitch contours and melodies, (2) to assess deficits in the central auditory system for sensory encoding and (3) to explore the effects of music training on brain plasticity in CI users" (p. 10). They also suggest that with multi-feature paradigms (see Section 4.2 below), more systematic information may be obtained about the processing of pitch contour changes in CI users.

\subsection{Multi-feature MMN paradigms}

The MMN studies reviewed above report cortical activity in the so-called 'oddball' paradigm in which an occasional deviant is randomly introduced into sequences of standards (Näätänen, 1992). These paradigms are time-consuming (often exceeding an hour) which is impractical for clinical purposes, such as when studying MMN in children with attention deficits (Huttunen-Scott et al., 2008) or CIs (Torppa et al., 2012). Furthermore, these paradigms test only for one type of sound deviant at a time, and thus present the deviants in a relatively simplified context. Thus, the studies conducted with oddball paradigms may not reflect the true discrimination capabilities of $\mathrm{CI}$ users in relation to more complex stimuli such as continuous speech or music, limiting the ecological validity of the results.

This is important, especially since recent MMN studies of auditory expertise indicate that to disclose fine-grained processing differences between participants, the stimuli need to consist of realistic, complex musical material. For example, in an oddball sequence, Koelsch et al. (1999) presented for NH violinists and nonmusicians slightly mistuned tones in the context of simple sinusoidal tones or perfect major chords. When the frequency difference was small, the difference between the subgroups was found only for the chord stimulus, where the slightly impure chords elicited an MMN in professional musicians only. Moreover, MMN results differ between different kinds of $\mathrm{NH}$ musicians depending on the complexity of musical stimulus (Seppänen et al., 2007). Importantly, in several types of disorders characterized by atypical perception, such as autism, schizophrenia or congenital amusia, stimulus complexity is a crucial factor (For a review see Näätänen et al., 2011), which is also expected for CI recipients. All these aspects emphasize the need for new, complex and short paradigms especially when the neural music perception of $\mathrm{CI}$ recipients is studied.

As a solution to these challenges, Näätänen and colleagues have introduced a new multi-feature paradigm in which MMNs are recorded for five different feature changes in less than $20 \mathrm{~min}$ (Näätänen et al., 2004). In the traditional oddball MMN paradigm, there are normally $80-90 \%$ repetitive standard stimuli and $10-20 \%$ deviants whereas multi-feature paradigms can use 50\% standard sounds and $50 \%$ deviants. The standards alternate with different types of deviants. The assumption is that the deviant stimuli reinforce the expectations for those features that they share with the standard. This allows for several MMNs to be independently elicited for different auditory attributes, making the duration of the experiment considerably shorter. Importantly, no difference is observed between the MMNs recorded with multi-feature paradigms and the ones obtained in the traditional 'oddball' paradigm (Näätänen et al., 2004; Pakarinen et al., 2007).

The first multi-feature paradigm used for adult CI listeners was introduced by Sandmann et al. (2010: see Table 2). In this paradigm, 
every other tone was a standard which was a synthesized clarinet tone. Every other tone was one of the deviants (change in $\mathrm{f}_{0}$ (pitch), intensity or duration). There were four magnitudes of changes for each deviant type, leading to 12 deviants altogether. Sandmann et al. (2010) found, that adult CI users had difficulties in discriminating small changes in the acoustic properties of musical sounds, judging from the small MMN amplitudes elicited. The authors concluded that an impaired discrimination ability in different acoustic dimensions may, at least partly, account for the poor musical sound perception in CI users. Hence, this type of paradigm could be of substantial clinical value by providing a comprehensive profile of the extent of the restored hearing in CI users.

An inverse relationship was found between the MMN amplitude and the duration of profound deafness; nevertheless, there was also evidence for experience-related plastic cortical changes as a function of the duration of CI use (Sandmann et al., 2010). Importantly, a relationship between speech intelligibility (tested by The Oldenburg Sentences Test) and the MMN amplitudes for frequency and intensity deviations was also found. Thus, MMN responses could be used as an objective marker for assessing auditory rehabilitation in different acoustic dimensions following cochlear implantation. An objective marker would be particularly helpful for young children who receive implants before language acquisition by indicating whether the CI provides sufficient stimulation to allow the normal development of the central auditory functions (Sharma, 2006).

\subsection{Musical multi-feature paradigm - distinct MMNs for several musical features}

In their subsequent study on the residual neural processing of musical sound features in adult CI users, Timm et al. (2014) used an adapted version of the recently developed musical multi-feature MMN paradigm of Vuust et al. (2011), enabling them to determine auditory discrimination of 6 different types of sound-feature changes inserted within a musically enriched stimulus setting lasting for 20 min only. The musical multi-feature paradigm is an extension of the "optimal paradigm" (Näätänen et al., 2004) but with a richer musical context and higher complexity obtained by presenting standards and deviants within an "Alberti bass" configuration. This configuration is commonly used in the Western musical culture in both classical and improvisational music genres. In the musical multi-feature paradigm, deviant sound features (such as pitch, timbre, intensity and rhythm) are embedded in the "Alberti bass" where 3 different pitches alternate in a 4-note pattern changing over the 4 keys (Fig. 4). The stimuli therefore provide a more musical context than the original multi-feature paradigm. Indeed, the musical multi-feature paradigm has shown MMN differences between different kinds of musicians, which were closely related to the style-specific aspects of the music practiced (Vuust et al., 2012).

Timm and her colleagues found five significant MMNs in the CI users, while obtaining significant results for all the six different deviant categories in $\mathrm{NH}$ control participants. The MMNs of the $\mathrm{CI}$ users were lower in amplitude and their peak latency was longer than those of the control subjects for feature deviations of pitch and guitar timbre, whereas no differences were found for intensity and saxophone timbre (Fig. 5). Furthermore, the MMNs in the CI users reflected the behavioral scores. These results indicate, according to the authors, that even though the $\mathrm{CI}$ users are not performing on the same level as the control subjects they have potential processing abilities for music listening. However, MMNs in CI users for rhythm were absent, indicating diminished feature detection ability for rhythmic changes within a melodic pattern under passive conditions.

The results of Timm and her colleagues extend the view of the neural abilities for musical feature processing in the adult CI users who were implanted after their childhood. Importantly, this study showed that, in a music-like stimulation paradigm, the brains of $\mathrm{CI}$ recipients are able to extract more information from sound than previously reported, as indexed by the distinct MMNs for several musical features. This indicates the existence of residual encoding abilities in the brains of adult $\mathrm{CI}$ users which provide a ground for possible effective rehabilitation programs. The authors further propose that this short multi-feature MMN paradigm implemented in their study may be adopted for clinical routine as it may yield objective data of the capability of the current implants in an everyday listening situation. However, future research in the ERP method needs to reach sensitivity at the single subject level "to enhance reliability of individual multi-attribute profiles of sound discrimination abilities" (p. 9).

\subsection{Cortical processing of musical sounds in children with CIs}

Torppa et al. (2012) studied for the first time the cortical processing of musical sounds in children with CIs. The participants were 24 early-implanted children (mean age 6 years 10 months) who had had their unilateral implants for at least 22 months prior to the ERP recording. The standard stimulus was a natural piano tone D4 in the Western musical scale $(295 \mathrm{~Hz})$ with a duration of $200 \mathrm{~ms}$. The deviant stimuli differed from the standard stimuli either in pitch (with all harmonics changing with the fundamental frequency), duration, intensity, gap (a short gap in the middle of the tone), or musical-instrument sound (timbre). For all deviants, the deviation was presented at three magnitudes of change. In the stimulus blocks, the standard and deviant stimuli alternated, with the deviant stimuli being presented in a random order in every other stimulus position (see Näätänen et al., 2004). The authors found that this multi-feature MMN paradigm yielded significant P1, MMN, and P3a responses in a short recording time of $36 \mathrm{~min}$. They concluded that with natural sounds presented in the multi-feature paradigm, it is possible to obtain new information about the development and plasticity of the cortical processing of musical stimuli. Further, in these early-implanted CI children, the MMN responses indicated less accurate change detection than that in age-matched $\mathrm{NH}$ children which probably reduced involuntary attention shifts for changes in musical instruments. Importantly, it was proposed by the authors that these difficulties might be alleviated or abolished with appropriate, multisensory auditory

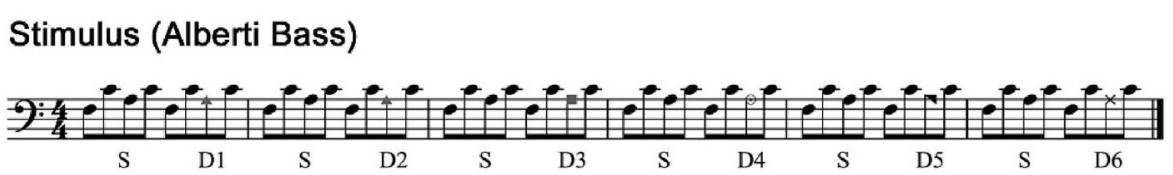

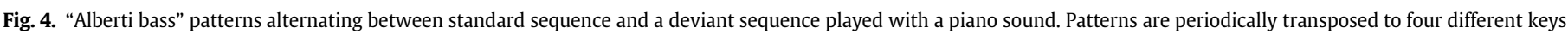

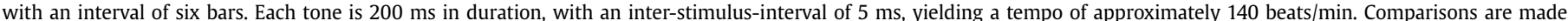

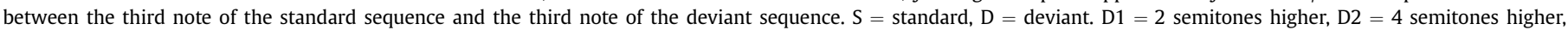
D3 = guitar sound, D4 = saxophone sound, D5 = $12 \mathrm{~dB}$ reduction, D6 = $60 \mathrm{~ms}$ earlier. The figure is from Timm et al. (2014). Licensed under CC-BY. 


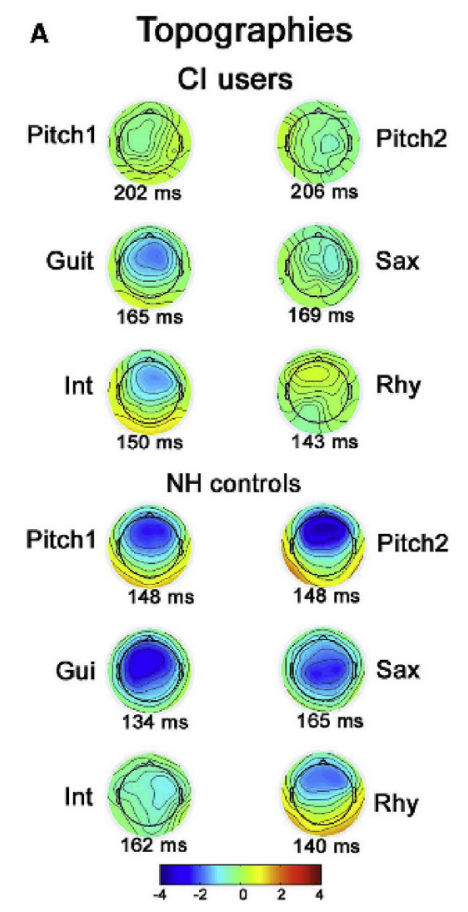

B Difference waves $\mathrm{Cl}$ users

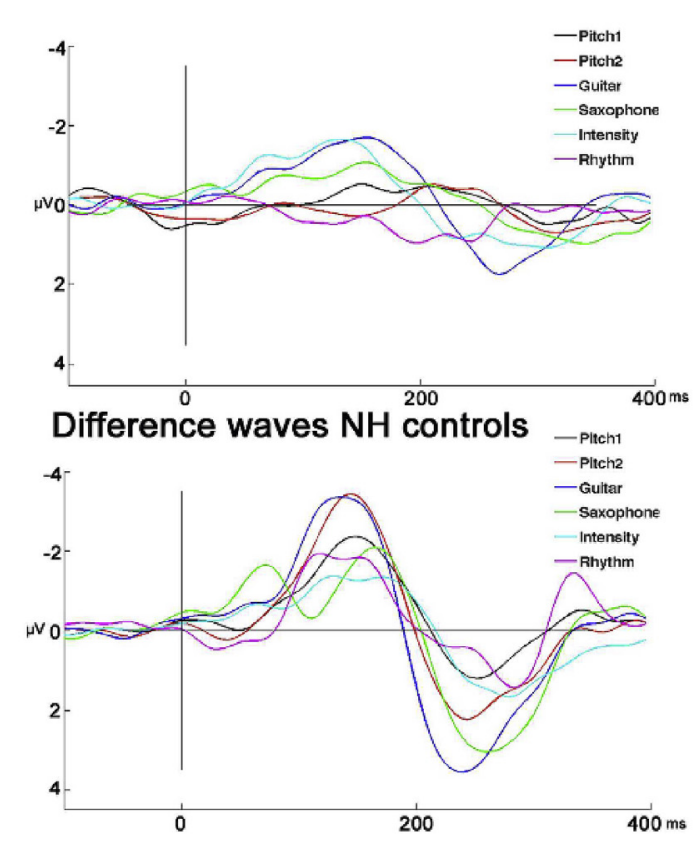

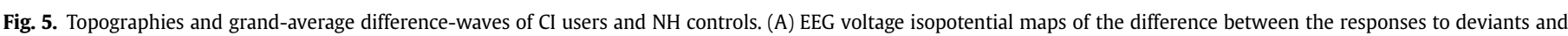

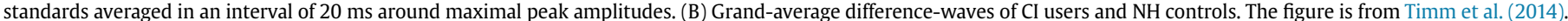
Licensed under CC-BY.

\section{rehabilitation.}

In addition, according to the authors, their results suggest that despite the different sensory information provided by a CI, early and unilaterally implanted $\mathrm{CI}$ users process the acoustic properties of piano tones with natural harmonics and a fast presentation rate with the same neurocognitive mechanisms as the NH control children, as indexed by the MMN and P3a responses. These similar neurocognitive mechanisms may allow $\mathrm{CI}$ children to derive from music the same self-regulatory, emotional and arousing effects as the $\mathrm{NH}$ population, which is an extremely important factor in attracting them into the world of music and sound - and may explain why early-implanted children enjoy music (Trehub et al., 2009).

\subsection{MMNs in CI children who sing}

In their subsequent study on music perception in children with CI, Torppa et al. (2014b) aimed at determining whether singing could facilitate auditory perception and attention in children with CI. The ERPs were recorded twice: at T1 and T2, 14-17 months apart. The ERP indices of discrimination (the MMN) and attention shift (P3a) were recorded to a number of different sound changes (see Torppa et al., 2012; above). The study showed that the duration MMN became larger in amplitude from T1 to T2 in the control group only. Importantly, the $\mathrm{CI}$ group with singing showed enhanced P3a types of responses across all the types of stimulus change at $\mathrm{T} 2$. In contrast, the non-singing $\mathrm{CI}$ group had an enlarged pitch MMN with no P3a enhancement, and their P3a became smaller and later over time. According to the authors, their results imply an augmented development of neural networks for attention and more accurate sound discrimination associated with singing: singing may enhance perceptual and attentional functions related to music and, possibly, sounds in general. This suggests that singing which requires no expensive musical instruments and is thus available for everyone, might be most beneficial for the rehabilitation and the quality of life of children with CIs (Fig. 6).

\subsection{MMN for music in adolescent CI users}

Recently, Petersen et al. (2015) studied the behavioral and neural correlates of music perception in the new generation of prelingually deaf adolescents who grew up with CIs. The MMN was recorded using a musical multi-feature paradigm (Timm et al., 2014) in adolescent $\mathrm{CI}$ users and in $\mathrm{NH}$ mates. The authors reported significant MMNs in the adolescent $\mathrm{CI}$ users for deviations in timbre, intensity, and rhythm, indicating the presence of residual neural prerequisites for musical feature processing. By contrast, only one of the two pitch changes used elicited an MMN in the $\mathrm{CI}$ users. This pitch-discrimination deficit was supported by behavioral measures, in which the $\mathrm{CI}$ users scored significantly below the level of the $\mathrm{NH}$ control participants. Overall, the MMN amplitudes were significantly smaller in the $\mathrm{CI}$ users than those in the controls, suggesting a poorer music discrimination ability. This shows significant brain responses to musical feature changes in prelingually deaf adolescent CI users and their associations with behavioral measures, implying the presence of neural predispositions for at least some aspects of music processing.

\section{Practical issues in MMN recording and analysis in CI recipients}

When recording the ERPs from $\mathrm{CI}$ recipients, there are a number of challenges relating to the fact that the implant transmits sound to the cochlea using electrical impulses. Below we summarize these challenges and review the available methods for removing artefacts, averaging data and determining the amplitude and latency of the signal.

\subsection{Within-block MMN vs. across-block MMN}

Several paradigm types and designs for MMN quantification have been used in previous MMN studies in CI listeners. Kraus et al. 


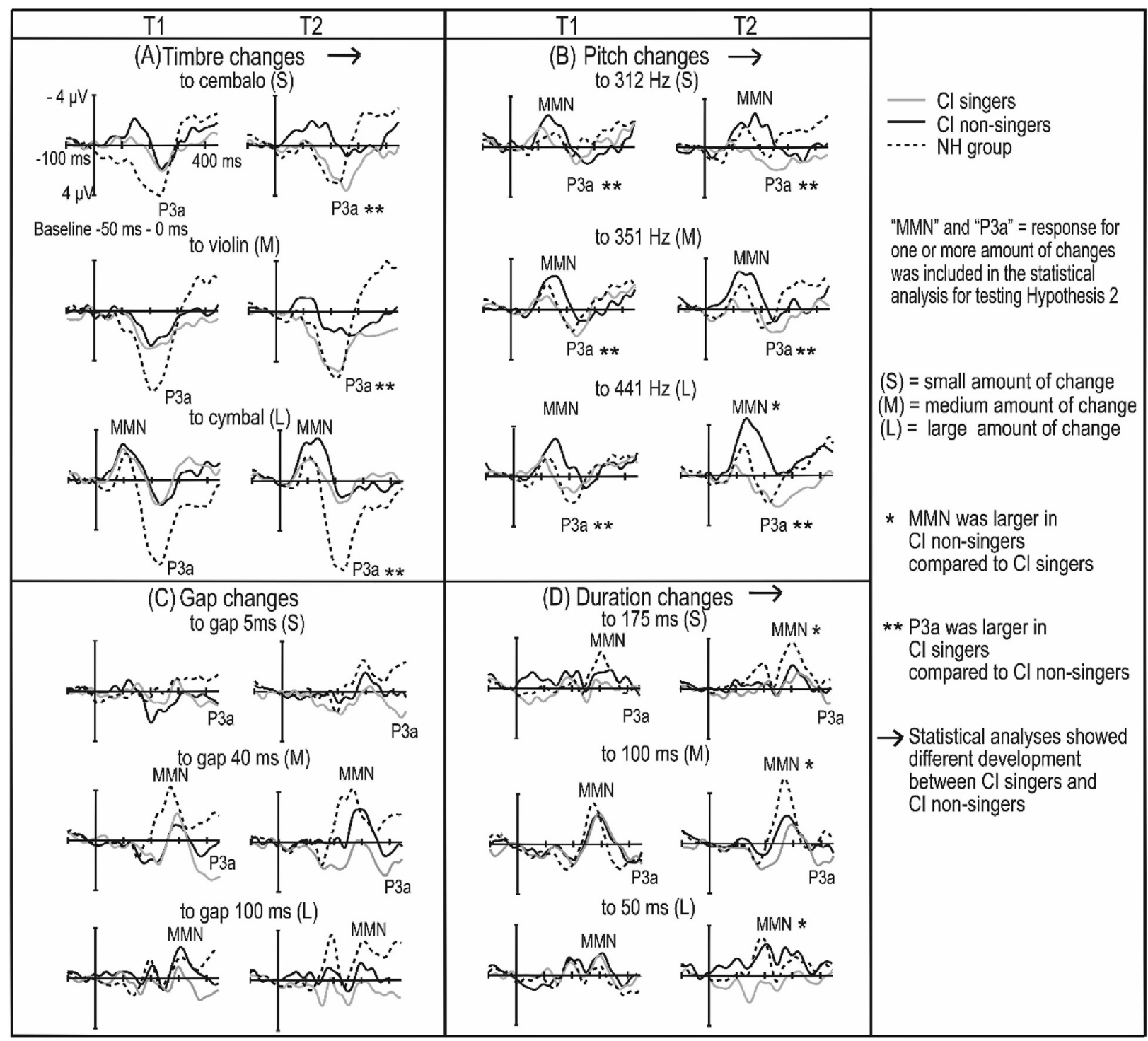

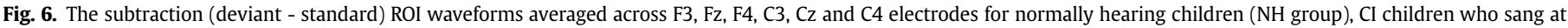

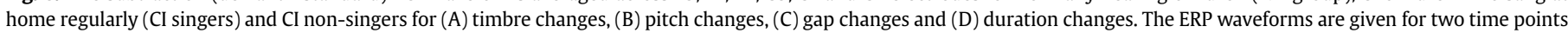
of the measurements (T1 and T2 on the left and right in each panel, respectively). The Figure is from Torppa et al. (2014b). Licensed under CC-BY.

(1993) quantified the MMN by subtracting the grand average ERP response to standard (computer-generated/da/) from response to deviant (computer-generated/ta/), both obtained from the same presentation sequence (block), here called the within-block MMN (see also Vavatzanidis et al., 2015). This procedure is the most common for the MMN studies in adult CI listeners (see Table 2).

Kraus et al. (1993) also presented deviant/ta/alone, which they called a control condition, because the MMN should occur in response to the deviant stimulus only when it is presented in the oddball paradigm and not when the deviant stimulus is presented alone. They quantified the MMN by subtracting the ERP response to the/ta/in the control condition from the response to the deviant/ta/. Hence they quantified the MMN across two different presentation sequences (here called across-block MMN). They stated that because the MMN was seen in the control condition also, the difference waveform truly represents a neurophysiological mismatch response to stimulus differences and that the MMN was not simply a response to the peripheral processing of acoustic differences.

A variation of this across-block MMN quantification was introduced by Ponton and Don (1995; see also Wable et al., 2000). They elicited a pitch change by stimulating one pair of electrodes in basal and one pair in apical electrodes. Duration change was elicited by altering the number of electrical pulses contained within a stimulus train (for NH subjects, the MMN was elicited with corresponding trains of acoustic clicks). The standard from the first block became the deviant for the second block, and the deviant from the first block became the standard for the second block. The MMN was quantified based on the subtraction of responses evoked by a same stimulus, but presented as the standard in one presentation block and as the deviant in the next presentation block. The authors chose this procedure to minimize the magnitude of the physical components related to the MMN, which was important because the physical components may be more prominent for short-duration acoustic stimuli or for brief electrical pulses than for longduration tone-bursts or acoustically complex signals. In general, the waveforms and the MMN responses acquired with across-block design should reflect activity related purely to contextual differences and not activity related to physical differences in the stimuli. 


\subsection{Dealing with electric artefact from the $C I$}

A major challenge with measuring MMN and other ERP responses with CIs is electrical artefacts. Electrical artefacts from a brief stimulus (up until $40 \mathrm{~ms}$ ) can be separated from the ERP signal because the artefacts precede the response in time (Ponton and Don, 2004; Friesen and Picton, 2010). However, for longer, ecologically valid musical or speech stimuli, the CI artefact usually continues through the response (see Fig. 1 in Gilley et al., 2006). This is the case especially for the new generation of CIs. In the pioneering CI MMN studies (up until years 2002-2005), the CI subjects typically used devices running with bipolar electrodes (bipolar stimulation mode). This stimulation mode produces substantially smaller artefacts as compared to the now commonly used monopolar-coupled electrodes. Moreover, the remote return electrode placement for monopolar stimulation varies across devices, causing variation in the distribution of the artefacts (Gilley et al., 2006). It is worth to note, that the artefact was not "a big deal" in studies carried over before year 2006 or so, not even for the studies with speech stimuli: the subjects in whom the artefact overlapped with brain activity could just be excluded from the analysis or were not discussed at all (see Tables 1 and 2).

If one has access to multi-channel ERP recording systems, one possible technique for artefact removal is the principal components analysis (PCA) (Casarotto et al., 2004; Croft \&Barry, 2002; Jung et al., 2000a) which has been used in at least one study on CI participants (Rahne et al., 2014; Table 2). This statistical technique decorrelates data into a series of factors (PCs) based upon the amount of variance explained. The first PC explains the largest amount of variance in the original dataset, the second PC the second largest amount of variance, and so forth. However, the PCA may not completely differentiate the biologic artefacts from the neural responses. Moreover, some loss of EEG data may occur when using this approach. Ideally, a decomposition of underlying activity should maximize the independence of the sources contributing to the EEG activity and minimize the loss of EEG data, which is important in the further statistical analyses after the removal of the unwanted signals (Gilley et al., 2006; for a review).

Therefore, the most popular artefact-reduction technique used nowadays, requiring multi-channel recordings, is Independent Component Analysis (ICA) (Jung et al., 2000a, b; Delorme and Makeig, 2004; Makeig et al., 2004). The ICA both decomposes the data unmixed into temporally independent and spatially fixed components and minimizes the loss of EEG data. Each ICA component corresponds to a scalp topography which represents the relative projection strength of the component at each scalp sensor (Gilley et al., 2006). Based on the findings by Gilley et al. (2006), the four principles as follows are typically used to identify the CI artefact: (1) the scalp projections of the component's activity revealed a centroid on the side of the implanted device; (2) the onset of the component's activity occurred at the onset of the auditory stimulus; (3) the offset of the component's activity occurred at the offset of the auditory stimulus; and (4) the duration of the component's activity was constant throughout the duration of the auditory stimulus.

In addition, the saw-tooth like spectral distribution of activity in the IC power spectrum is used to identify the artefact (see Torppa et al., 2012; Supplementary Figure S3). The ICA preserves ERP components in CI subjects well, and makes it possible to use stimuli with high frequency resolution, complexity and ecological validity, such as musical sounds (Viola et al., 2011). Viola et al. (2011) also found in their work with CI subjects that the ICA well preserves the individual differences of ERP responses, and further, that peak latencies of the ICA-corrected responses correspond well to uncorrected responses from $\mathrm{NH}$ subjects in the 100-300 ms window.
Artefact-reduction with the ICA has been successfully used in several MMN studies on CI listeners (Sandmann et al., 2010; Zhang, 2011, Zhang et al., 2013a, b; Timm et al., 2012, 2014, Torppa et al., 2012, 2014b; Petersen et al., 2015; see Tables 1 and 2). Artefact reduction with the ICA can be very time-consuming. However, Viola et al. (2012) have developed an ICA-based semi-automatic CI Artefact Correction (CIAC) algorithm (provided as an open source plugin to be used with the EEGLAB toolbox).

Unfortunately, many researchers or CI clinics may not have access to multi-channel recording systems. If this is the case, one option is to use a short stimulus, for which the neural response follows the artefact as described above. However, also other methodologies have been developed. The subtraction technique might be one method to eliminate electrical artefact (Friesen and Picton, 2010). This technique is based on the findings that the neural response increases in amplitude with an increasing ISI, reaching a maximum when the ISI is $10 \mathrm{~s}$ on average (for a review see, Näätänen et al., 2007). When the ISI is two seconds or longer, the response is several times larger in amplitude than when the interval is $0.5 \mathrm{~s}$. Given that there is only an amplitude difference and that there is little if any latency change, then this procedure should then remove the artefact and leave a difference waveform that is similar to the unsubtracted response.

The authors (Friesen and Picton (2010) found this methodology promising. However, they bypassed the patient's sound processor and stimulated the implant directly and suspected that this technique may not work as well for responses collected in the sound field. Nevertheless, very recently, Vavatzanidis et al. (2016) suggested that subtracting physically similar responses (like subtracting a stimulus as a standard in one block from that being a deviant in another block) should ensure that the CI artefact is eliminated from the signal. Indeed, using this approach, Vavatzanidis et al. (2016) found no hint of the artefact in the resulting difference signals, even though the stimulus was presented in free field.

Singh, 2004 have introduced a method where they reposition the electrode leads away from the CIs, and remove residual artefact mathematically offline. First they created an average of the artefact from one of the contaminated recording channels. Then they subtracted this from all the channels and all epochs proportionally, after first calculating their transmission coefficients. Using these techniques, they managed to improve the quality of their recording.

One possible method for the $\mathrm{Cl}$-artefact reduction is to optimize the differential reference (ODR). Gilley et al. (2006) found that the electrical activity generated by the electrode array is broadly distributed on the scalp and generally has a dipole distribution with peak amplitude levels near the active stimulation electrode(s) located within the cochlea and a common extra-cochlear return electrode remotely located beneath the scalp. The authors recorded auditory ERPs at $\mathrm{Cz}$ relative to a remote reference electrode and tried to minimize the artefact (differentially measured at $\mathrm{Cz}$ ) by selecting an optimal reference electrode site. They assumed that artefact seen at a specific electrode location (e.g., $\mathrm{Cz}$ ) would be cancelled by placing the reference electrode at a location with the same artefact as that at $\mathrm{Cz}$. Results from this experiment indicated that with this technique, the artefact could be minimized. However, future studies are needed to confirm whether this procedure is optimal for reducing the $\mathrm{CI}$ artefacts.

Recently, Mc Laughlin et al. (2013) introduced a new technique for artefact removal. To this end, they used a single-channel, highsample rate $(125 \mathrm{kHz})$, and high-bandwidth $(0-100 \mathrm{kHz})$ acquisition system. At first, they identified a high-frequency artefact reflecting the stimulation pulse rate (HFA), and a direct current artefact showing a time-varying relationship to the pulse amplitude (DCA). A hardware or software low-pass filter with a cutoff 
frequency at around 50 or $35 \mathrm{~Hz}$ reduced the HFA. The DCA was reduced with a randomization procedure. Mc Laughlin et al. (2012) and Beynon et al. (2008, 2012) have developed a system with which late AEPs can be measured in $\mathrm{CI}$ subjects using the $\mathrm{CI}$ itself as a recording device, removing the need to attach scalp electrodes or to have a dedicated acquisition system. As Mc Laughlin et al. (2013) state, combining this $\mathrm{CI}$ recording technique with a singlechannel artefact-cancellation approach is an interesting possibility to record MMN responses in the future.

\subsection{Electrodes used for recording and quantification of the $M M N$}

In several studies, only one electrode has been used for the recording and quantification of an MMN (see Tables 2 and 3). While this is beneficial from the perspective of clinical recordings, this is not always the optimal way if there is a possibility for multichannel recordings. One technique for MMN quantification that reduces noise is to form a region of interest (ROI) channel by averaging ERP signals for each subject across several electrodes for MMN quantification. Typically, the fronto-central electrodes are used because there the MMN reaches the largest values (Lang et al., 1995). For example, Roman et al. (2005a,b), averaged the ERPsignals from 8 fronto-central electrodes (F3, FZ, F4, FC1, FC2, C3, C4 and CZ). Koelsch et al. (2004) formed frontal, parietal, and left and right frontal ROI signals (frontal: Fz, F3, F4, FC3, and FC4; parietal: Pz, P3, P4, CP5 and CP6; frontal left: F3, F7, FC3, FT7; frontal right: F4, F8, FC4, FT8). Sandmann et al. (2010) averaged (after ICA) the ERP signals from F1, Fz, F2, FC1, FCz and FC2 and Torppa et al. (2014b) from the F3, Fz, F4, C3, Cz, and C4 electrodes (see also Zhang et al., 2013a). As Roman et al. (2005a,b) state, these individual ROI waveforms may reveal the MMN more precisely.

\subsection{Averaging}

Traditionally, the average of the ERP signals is calculated for further ERP analyses. However, there is evidence that calculating the median instead of the average is optimal in cases where the data are of high quality in general, but some overlapping noise seen as extreme values is expected, which is typical when studying young children (Yabe et al., 1993). Based on this, Torppa et al. (2012, 2014b) chose to use this median method. When using this procedure, first the trials of each individual are grouped by stimulus type. As a second step, the median value of the signal-amplitude values of one sample point are taken as representative of that sample point. Here, the resulting curve from an individual consists of the samples having the median amplitude over the accepted trials. This median method is theoretically better than the normal averaging method. At least when using the ICA for reducing artefacts related to eye blinks, muscular activity and electric artefact caused by the functioning of Cls, the median and averaged signals are rather similar as shown by Torppa et al. (2014b; Supplements 2 and 3).

\subsection{MMN-amplitude quantification}

In the first MMN study involving CI users (Kraus et al., 1993), the MMN magnitude was quantified from the grand averages by measuring the amplitude from the preceding peak to the midpoint of the MMN (onset-to-peak) and from the midpoint to the end of the MMN waveform (peak-to-offset) as well as the area of the MMN waveform. In recent studies, the individual MMN amplitudes are computed as the mean amplitudes in group and deviant-specific intervals at a certain time window (48 $\mathrm{ms}$ in Sandmann et al., 2010; $30 \mathrm{~ms}$ in Torppa et al., 2014a) around the respective grand-

Table 3

Multi-feature paradigm studies.

\begin{tabular}{|c|c|c|c|c|c|c|c|}
\hline \multirow[t]{2}{*}{ Authors } & \multirow{2}{*}{$\begin{array}{l}\mathrm{N} \text { of } \mathrm{CI} \text { users } \\
\text { (uni-/bilateral); } \\
\text { age; age at } \mathrm{CI}\end{array}$} & \multicolumn{2}{|l|}{ Stimuli for the MMN } & \multirow{2}{*}{$\begin{array}{l}\text { Duration of } \\
\text { std/deviant } \\
(\mathrm{ms}) \text {; ISI or } \\
\text { SOA (ms) }\end{array}$} & \multirow{2}{*}{$\begin{array}{l}\text { Total N of } \\
\text { electrodes (those } \\
\text { used for MMN } \\
\text { analyses)/Across/ } \\
\text { within-block }^{1}\end{array}$} & \multirow{2}{*}{$\begin{array}{l}\text { Artifact } \\
\text { reduction } \\
\text { method }\end{array}$} & \multirow{2}{*}{$\begin{array}{l}\text { Other ERPs and } \\
\text { behavioral methods }\end{array}$} \\
\hline & & Standard & Deviants & & & & \\
\hline $\begin{array}{l}\text { Sandmann } \\
\text { et al. (2010) }\end{array}$ & $\begin{array}{l}12 \text { ( } 8 \text { uni-lateral/ } \\
4 \text { bilateral); } \\
38-70 \text { years; } \\
37-64 \text { years }\end{array}$ & $\begin{array}{l}\text { A clarinet tone, } \\
\text { f0 }=440 \mathrm{~Hz} \\
\text { (synthesized) }\end{array}$ & $\begin{array}{l}\text { Pitch, intensity (decrement), } \\
\text { duration (decrement). } \\
4 \text { levels of magnitude. }\end{array}$ & $\begin{array}{l}150 ; \\
\text { ISI, SOA? }\end{array}$ & $\begin{array}{l}\text { 60; (ROI signal from } \\
\text { F1, Fz, F2, FC1, FCz, } \\
\text { FC2)/within-block }\end{array}$ & ICA & $\begin{array}{l}3 \text { alternative forced } \\
\text { choice (AFC): } \\
\text { stim = EEG stim. } \\
\text { Clinical data: } \\
\text { Freiburg, monosyllabic } \\
\text { words test (\%) } \\
\text { Oldenburg SIN (dB) }\end{array}$ \\
\hline $\begin{array}{l}\text { Torppa et al., } \\
\text { 2012, 2014b }\end{array}$ & $\begin{array}{l}22 \text { (unilateral); } \\
4 \text { to } 13 \text { years; } \\
\leq 3 \text { years }\end{array}$ & $\begin{array}{l}\text { A natural piano } \\
\text { tone, f0 } 295 \mathrm{~Hz}\end{array}$ & $\begin{array}{l}\text { Every other tone a change } \\
\text { in F0 (pitch), timbre, } \\
\text { intensity (decrement or } \\
\text { increment), duration } \\
\text { (decrement) or a gap in } \\
\text { the middle of the tone. }\end{array}$ & $\begin{array}{l}200 ; \\
\text { SOA } 480\end{array}$ & $\begin{array}{l}64 \\
\text { (MMN ampl: the } \\
\text { mean from F3, Fz, } \\
\text { F4, C3, Cz and C4; } \\
\text { For latencies: Fz)/ } \\
\text { within-block }\end{array}$ & ICA & $\begin{array}{l}\text { 2012: P1 P3a } \\
\text { 2014b: P3a, the singing } \\
\text { accuracy of the CI } \\
\text { children was evaluated } \\
\text { (rhythm, pitch, lyrics). }\end{array}$ \\
\hline $\begin{array}{l}\text { Timm et al., } \\
2014\end{array}$ & $\begin{array}{l}12 \text { (unilateral); } \\
21-56 \text { years; } \\
13-53 \text { years }\end{array}$ & $\begin{array}{l}\text { Alberti bass figure } \\
\text { with piano sound. } \\
4 \text { different major keys }\end{array}$ & $\begin{array}{l}\text { Pitch: } 2 \text { semitones; } \\
4 \text { semitones } \\
\text { Timbre: saxophone, guitar } \\
\text { Intensity: } 12 \mathrm{~dB} \\
\text { Rhythm: } 60 \mathrm{~ms}\end{array}$ & $\begin{array}{l}200 \\
\text { ISI } 5\end{array}$ & $\begin{array}{l}30 \\
\text { (MMN ampl: mean } \\
\text { across all electrodes } \\
\text { in } 40 \text { ms time } \\
\text { windows; MMN } \\
\text { significance } \\
\text { analysis against } \\
0 \text { baseline on Fz/ } \\
\text { within-block }\end{array}$ & ICA & $\begin{array}{l}\text { Musical multi-feature } \\
\text { discrimination test }\end{array}$ \\
\hline $\begin{array}{l}\text { Petersen } \\
\quad \text { et al., } 2015\end{array}$ & $\begin{array}{l}11 \text { ( } 9 \text { bi-lateral } / 2 \\
\text { bimodal); } \\
15.6-18.8 \text { years; } \\
2.2-14.9 \text { years }\end{array}$ & Same as Timm et al. & Same as Timm et al. & $\begin{array}{l}\text { Same as } \\
\text { Timm et al. }\end{array}$ & $\begin{array}{l}30(\mathrm{Fz}) / \text { within- } \\
\text { block }\end{array}$ & ICA & $\begin{array}{l}\text { Musical multi-feature } \\
\text { discrimination test, } \\
\text { Dantale II tests }\end{array}$ \\
\hline
\end{tabular}

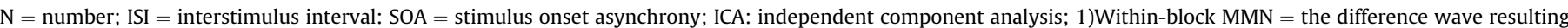

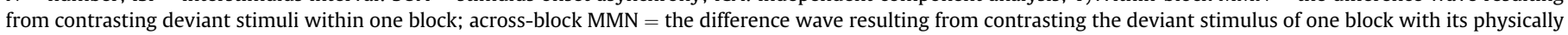
identical counterpart of the another block where it is presented as a standard stimulus. 
average negative peak amplitude in the difference signal in the time window where the MMN is expected. A measure of the duration of the MMN has also been used (for example, Singh, 2004; Table 1).

\subsection{MMN peak latency quantification}

The peak latencies of the MMN responses are usually analyzed from the difference waveforms, where the peak latency of the MMN is measured as the most negative peak after stimulus onset or more usually, at a specified time window. The MMN peak latencies can be calculated from one channel where the MMN is the largest in amplitude, typically from Fz, or from the ROI-signal (for example, Petersen et al., 2015; Torppa et al., 2014b). When the peak latencies of individuals are calculated in a specified time window, in optimal cases, the time window for calculation is the same as the time window for the MMN mean-amplitude calculation (for example, Petersen et al., 2015). However, sometimes an inspection of the data suggests that the time window for amplitude analysis is not optimal for peak latency analyses (peak latencies of some individuals lie outside of this time window resulting from polarity changes at the mastoid or for example at PO8; see Sandmann et al., 2010). In this case, it can be relevant to use different time windows for latency and amplitude analyses (for example, Torppa et al., 2012). The peak latencies of the duration- and gap-MMNs are corrected in relation to deviation onset, while the peak latencies of other MMNs are determined in relation to stimulus onset.

The jackknife-based approaches can sometimes provide more accurate estimates of latency differences than the approach of analyzing single-subject evoked potentials (Miller et al., 2009). Here, the MMN peak latencies are measured by using the jackknifebased approach (Kiesel et al., 2008) combined with the latency measurement of the most negative peak in the difference waves after stimulus onset. In the procedure of jackknifing, the peak latencies are measured for each of $\mathrm{n}$ grand average waveforms, with each of the grand average waveforms computed from a subsample of $\mathrm{N}-1$ of the $\mathrm{N}$ individual participants. This approach has been used for instance by Sandmann et al. (2010).

\section{Summary and conclusions}

In the present paper, we have reviewed the existing literature regarding EEG recording of the Mismatch Negativity Response in persons with severe to profound hearing loss who listen by means of a cochlear implant. The literature strongly indicates that the MMN provides an objective and quantitative assessment of the functioning of the $\mathrm{Cl}$ in children, adolescents and adults. MMN measurements hence pinpoint the potential problem areas for attempts at remediation. Furthermore, the MMN can be used for monitoring the gradual improvement of auditory perception, particularly speech discrimination, after the $\mathrm{CI}$ implantation. The similarity of the MMN in CI users with that of control subjects suggests that despite the major differences in peripheral input, the brains of $\mathrm{CI}$ users process basic speech units in a very similar way.

Particularly in infant and child patients, an objective method for the assessment of the functioning of the $\mathrm{CI}$ is an absolute necessity. This can be realized by using the MMN since it does not require the understanding of task instructions or cooperation and can also be used as an index of these patients' sensory memory necessary for different cognitive performances. The MMN may also be used to evaluate the effectiveness of different training programs and rehabilitation intended for the improvement of the $\mathrm{CI}$ function of a patient. An additional advantage by the MMN is that it enables one to assess the preserved memory traces during the period of deafness preceding the $\mathrm{CI}$ installation.
Several studies have used the MMN to objectively assess the discrimination of different features of music such as pitch, timbre and rhythm. This has relevance for the future development of $\mathrm{CI}$ sound representation since the ability to appreciate music is an emerging criterion both for existing $\mathrm{CI}$ users and for $\mathrm{CI}$ candidates. In addition, it is relevant because of the shared resources in music and language, suggesting that speech perception and underlying aspects can be rehabilitated with musical activities or training. Implementing both odd-ball paradigms and the recently developed multi-feature paradigms, these studies suggest that the MMN is a valid and reliable tool for the evaluation of the $\mathrm{CI}$ performance with musical stimuli and in music listening.

This review also summarizes the practical issues linked to the recording and analysis of the MMN in $\mathrm{CI}$ recipients. In particular, the removal of electrical artefacts from the implant is challenging with a potential risk of data loss. Recent studies have successfully implemented Independent Component Analysis (ICA) and single channel artefact cancellation, which have reduced artefact noise and in general significantly improved the analysis of MMN recordings from CI users.

\section{Acknowledgements}

The authors wish to thank Anne Sofie Friis Andersen for her assistance on editing parts of the manuscript.

Risto Näätänen wishes to thank the Lundbeck Foundation, Copenhagen Denmark.

This research did not receive any specific grant from funding agencies in the public, commercial, or not-for-profit sectors.

\section{References}

Abbas, P.J., Hughes, M.L., Brown, C.J., Miller, C.A., South, H., 2004. Channel interaction in cochlear implant users evaluated using the electrically evoked compound action potential. Audiol. Neuro-Otol. 9, 203-213.

Agrawal, D., 2013. Electrophysiological responses to emotional prosody perception in cochlear implant users. NeuroImage Clin. 2, 229-238.

Alho, K., 1992. Selective attention in auditory processing as reflected by eventrelated brain potentials. Psychophysiology 29, 247-263.

Alho, K., Sainio, K., Sajaniemi, N., Reinikainen, K., Näätänen, R., 1990. Event-related brain potential of human newborns to pitch change of an acoustic stimulus. Electroencephalogr. Clin. Neurophysiol. 77, 151-155.

Archbold, S., Lutman, M.E., Marshall, D.H., 1995. Categories of auditory performance Ann. Otol. Rhinol. Laryngol. Suppl. 166, 312-314.

Arnoldner, C., Riss, D., Brunner, M., Durisin, M., Baumgartner, W.D., Hamzavi, J.S. 2007. Speech and music perception with the new fine structure speech coding strategy: preliminary results. Acta Otolaryngol. 127 (12), 1298-1303 [PMID: 17851892].

Asp, F., Mäki-Torkko, E., Karltorp, E., Harder, H., Hergils, L., Eskilsson, G., Stenfelt, S., 2012. Bilateral versus unilateral cochlear implants in children: speech recognition, sound localization, and parental reports. Int. J. Audiol. 51, 817-832.

Besson, M., Chobert, J., Marie, C., 2011. Transfer of training between music and speech: common processing, attention, and memory. Front. Psychol. 2, 94

Beynon, A.J., Luijten, B., Snik, A.F.M., 2008. The cochlear implant as an EEG-system: a feasibility study to measure evoked potentials beyond the ecap. In: 10th International Conference on Cochlear Implants and Other Implantable Auditory Technologies. San Diego.

Beynon, A.J., Luijten, B.M., Mylanus, E.A.M., 2012. Intracorporeal cortical telemetry (ICT): capturing EEG with a CI. In: 7th International Symposium on Objective Measures in Cochlear and Brainstem Implants. Amsterdam, p. 24.

Bishop, D.V.M., Hardiman, M.J., 2010. Measurement of mismatch negativity in individuals: a study using single-trial analysis. Psychophysiology 47 (4), 697-705. http://dx.doi.org/10.1111/j.1469-8986.2009.00970.x.

Boons, T., Brokx, J.P., Dhooge, I., Frikns, J.H., Peeraer, L., Vermeulen, A., Wouters, J., van Wieringen, A., 2012. Predictors of spoken language development following pediatric cochlear implantation. Ear Hear. 33, 627-639.

Caldwell, A., Nittrouer, S., 2013. Speech perception in noise by children with cochlear implants. J. Speech Lang. Hear. Res. 56, 13-30.

Carlson, M.L.M., 2015. Magnetic resonance imaging with cochlear implant magnet in place: safety and imaging quality. Otol. Neurotol. 36, 965-971.

Caposecco, A., Hickson, L., Pedley, K., 2012. Cochlear implant outcomes in adults and adolescents with early-onset hearing loss. Ear Hear. 33, 209-220.

Carr, S.M., Rickard, N.S., 2015. The use of emotionally arousing music to enhance memory for subsequently presented images. Psychol. Music 1-13.

Casarotto, S., Bianchi, A.M., Cerutti, S., Chiarenza, G.A., 2004. Principal component 
analysis for reduction of ocular artefacts in event-related potentials of normal and dyslexic children. Clin. Neurophysiol. 115, 609-619.

Chatterjee, M., Shannon, R.V., 1998. Forward masked excitation patterns in multielectrode electrical stimulation. J. Acoust. Soc. Am. 103, 2565-2572.

Chausson, N., Wassouf, A., Pegado, F., Willer, J.C., Naccache, L., 2008. Eletrophysiology: mismatch negativity and prognosis of coma. Rev. Neurol. 164, 34-35.

Cheour-Luhtanen, M., Alho, K., Sainio, K., Rinne, T., Reinikainen, K., Pohjavuori, M. et al., 1996. The ontogenetically earliest discriminative response of the human brain. Psychophysiology 33, 478-481.

Ciocca, V., Francis, A.L., Aisha, R., Wong, L., 2002. The perception of Cantonese lexical tones by early-deafened cochlear implantees. J. Acoust. Soc. Am. 111 2250-2256.

Croft, R.J., Barry, R.J., 2002. Issues relating to the subtraction phase in EOG artefact correction of the EEG. Int. J. Psychophysiol. 44, 187-195.

Csepe, V., Osman-Sagi, J., Molnar, M., Gosy, M., 2001. Impaired speech perception in aphasic patients: event-related potential and neuropsychological assessment. Neuropsychologia 39, 1194-1208.

Csepe, V., Molnar, M., 1997. Towards the possible clinical application of the mismatch negativity component of event-related potentials. Audiol. Neurootol. 2, 354-369.

Cooper, W.B., Tobey, E., Loizou, P.C., 2008. Music perception by cochlear implant and normal hearing listeners as measured by the Montreal Battery for Evaluation of Amusia. Ear Hear 29, 618-626.

Cochlear implants. U.S. Department of Health \& Human Services, National Institute on Deafness and Other Communication Disorders. Retrieved from: http://www. nidcd.nih.gov/health/hearing/pages/coch.aspx. Accessed on July 18, 2014.

Debener, S., Hine, J., Bleeck, S., Eyles, J., 2008. Source localization of auditory evoked potentials after cochlear implantation. Psychophysiology 45, 20-24

Delorme, A., Makeig, S., 2004. EEGLAB: an open source toolbox for analysis of single-trial EEG dynamics including independent component analysis. J. Neurosci. Meth 134, 9-21.

Donaldson, G.S., Kreft, H.A., 2006. Effects of vowel context on the recognition of initial and medial consonants by cochlear implant users. Ear Hear 27, 658-677.

Draganova, R., Eswaran, H., Murphy, P., Huotilainen, M., Lowery, C., Preissl, H., 2005. Sound frequency change detection in fetuses and newborns, a magnetoencephalographic study. Neuroimage 28, 354-361.

Drennan, W.R., Rubinstein, J.T., 2008. Music perception in cochlear implant users and its relationship with psychophysical capabilities. J. Rehabil. Res. Dev. 45, 779-789.

Duncan, Connie C., et al., 2009. Event-related potentials in clinical research: guidelines for eliciting, recording, and quantifying mismatch negativity, P300, and N400. Clin. Neurophysiol. 120 (Issue 11), 1883-1908.

Francart, T., Osses, A., Wouters, J., 2015. Speech perception with F0mod, a cochlear implant pitch coding strategy. Int. J. Audiol. 54, 424-432.

Friederici, A.D., Friedrich, M., Christophe, A., 2007. Brain responses in 4-month-old infants are already language specific. Curr. Biol. 17, 1208-1211.

Friesen, L.M., Shannon, R.V., Baskent, D., Wang, X., 2001. Speech recognition in noise as a function of the number of spectral channels: comparison of acoustic hearing and cochlear implants. J. Acoust. Soc. Am. 110, 1150-1163.

Friesen, L.M., Picton, T.W., 2010. A method for removing cochlear implant artifact. Hear. Res. 259, 95-106.

Fu, Q.J., Galvin III, J.J., 2008. Maximizing cochlear implant patients' performance with advanced speech training procedures. Hear. Res. 242, 198-208.

Gantz, B.J., Tyler, R.S., Knutson, J.F., Woodworth, G., Abbas, P., McCabe, B.F. Hinrichs, J., Tye-Murray, N., Lansing, C., Kuk, F. et al., 1998. Evaluation of five different cochlear implant designs: audiologic assessment and predictors of performance. Laryngoscope 98, 1100-1 106.

Garza Villarreal, E.A., Brattico, E., Leino, S., Ostergaard, L., Vuust, P., 2011. Distinct neural responses to chord violations: a multiple source analysis study. Brain Res. 1389, 103-114.

Gaylor, J.M., Raman, G., Chung, M., Lee, J., Rao, M., Lau, J., Poe, D.S., 2013. Cochlear implantation in adults: a systematic review and meta-analysis. Jama Otolaryngol., Head Neck Surg. 139, 265-272.

Geers, A.E.A., 2003. Predictors of reading skill development in children with early cochlear implantation. Ear Hear. 24, 59S-68S.

Geers, A.E., Nicholas, J., Tobey, E., Davidson, L., 2016. Persistent language delay versus late language emergence in children with early cochlear implantation. J. Speech Lang. Hear. Res 59, 155-170.

Gfeller, K., Turner, C., Oleson, J., Zhang, X., Gantz, B., Froman, R., Olszewski, C., 2007 Accuracy of cochlear implant recipients on pitch perception, melody recognition, and speech reception in noise. Ear Hear. 28, 412-423.

Gilley, P.M., Sharma, A., Dorman, M., Finley, C.C., Panch, A.S., Martin, K., 2006. Minimization of cochlear implant stimulus artifact in cortical auditory evoked potentials. Clin. Neurophysiol. 117, 1772-1782.

Groenen, P., Snik, A., Van Den Broek, P., 1996. On the clinical relevance of mismatch negativity: results from subjects with normal hearing and cochlear implant users. Audiol. Neurootol 1, 112-124.

Hahne, A., Wolf, A., Müller, J., Mürbe, D., Friederici, A.D., 2012. Sentence comprehension in proficient adult cochlear implant users: on the vulnerability of syntax. Lang. Cognitive Process. 27, 1192-1204.

Hassepass, F., Stabenau, V., Maier, W., Arndt, S., Laszig, R., Beck, R., Aschendorff, A., 2014. Revision surgery due to magnet dislocation in cochlear implant patients: an emerging complication. Otol. Neurotol. 35, 29-34.

Hochmair, I., Nopp, P., Jolly, C., Schmidt, M., Schösser, H., Garnham, C., Anderson, I., 2006. MED-EL Cochlear implants: state of the art and a glimpse into the future.
Trends Amplif. 10 (4), 201-219 [PMID: 17172548].

Holden, L.K., Finley, C.C., Firszt, J.B., Holden, TA, Brenner, C., Ptts, L.G, Gotter, B.D., Vanderhoof, S.S., Mispagel, K., Heydebrand, G., Skinner, M.W., 2013. Factors affecting open-set word recognition in adults with cochlear implants. Ear Hear. 34, 342-360.

Hopyan-Misakyan, T.M.T., 2009. Recognition of affective speech prosody and facial affect in deaf children with unilateral right cochlear implants. Child. Neuropsychol. 15, 136-146.

Hu, Y., Loizou, P.C., 2008. A new sound coding strategy for suppressing noise in cochlear implants J. Acoust. Soc. Am. 124, 498-509.

Huttunen-Scott, T., Kaartinen, J., Tolvanen, A., Lyytinen, H., 2008. Mismatch negativity (MMN) elicited by duration deviations in children with reading disorder, attention deficit or both. Int. J. Psychophysiol. 69, 69-77.

Ilvonen, T., Kujala, T., Kozou, H., Kiesiläinen, A., Salonen, O., Alku, P., Näätänen, R. 2004. The processing of speech and non-speech sounds in aphasic patients as reflected by the mismatch negativity. Neurosci. Lett. 366, 235-240.

Johnson, J.M., 2009. Late auditory event-related potentials in children with cochlear implants: a review. Dev. Neuropsychol. 34, 701-720.

Jung, T.P., Makeig, S., Humphries, C., Lee, T.W., McKeown, M.J., Iragui, V., Sejnowski, T.J., 2000a. Removing electroencephalographic artifacts by blind source separation. Psychophysiology 37, 163-178.

Jung, T.P., Makeig, S., Westerfield, M., Townsend, J., Courchesne, E., Sejnowski, T.J., 2000b. Removal of eye activity artifacts from visual eventrelated potentials in normal and clinical subjects. Clin. Neurophysiol. 111, 1745-1758.

Kane, N.M., Butler, S.R., Cummins, B.H., 1993. Electrophysiological indicator of awakening from coma. Lancet 341, 688.

Kelly, A.S., 2005. Electrophysiological and speech perception measures of auditory processing in experienced adult cochlear implant users. Clin. Neurophysiol. 116, 1235-1246.

Kiefer, J., Hohl, S., Sturzebecher, E., Pfennigdorff, T., Gstoettner, W., 2001. Comparison of speech recognition with different speech coding strategies (SPEAK, CIS, and ACE) and their relationship to telemetric measures of compound action potentials in the nucleus CI 24M cochlear implant system. Audiology 40 (1), 32-42 (January/February 2001), ISSN 0020-6091.

Kiesel, A., Miller, J., Jolicoeur, P., Brisson, B., 2008. Measurement of ERP latency differences: a comparison of single-participant and jackknife-based scoring methods. Psychophysiology 45, 250-274.

Kileny, P.R., Boerst, A., Zwolan, T., 1997a. Cognitive evoked potentials to speech and tonal stimuli in children with implants. Otolaryngol. Head. Neck Surg. 117, 161-169.

Kileny, P.R., Zwolan, T.A., Boerst, A., Telian, S.A., 1997b. Electrically evoked auditory potentials: current clinical applications in children with cochlear implants. Am. J Otol. 18, 90-92.

Koch, D.B., Downing, M., Osberger, M.J., Litvak, L., 2007. Using current steering to increase spectral resolution in CII and HiRes 90K users (April 2007). Ear Hear. 28 (No.2), 38S-41S. ISSN 0196-0202.

Koelsch, S., Schröger, E., Tervaniemi, M., 1999. Superior pre-attentive auditory processing in musicians. NeuroReport 10, 1309-1313.

Koelsch, S., Wittfoth, M., Wolf, A., Muller, J., Hahne, A., 2004. Music perception in cochlear implant users: an event-related potential study. Clin. Neurophysiol. $115,966-972$.

Kral, A., Kronenberger, W.G., Pisoni, D.B., O'Donoghue, G.M., 2016. Neurocognitive factors in sensory restoration of early deafness: a connectome model. Lancet Neurol. 15, 610-621.

Kral, A., O'Donoghue, G.M., 2010. Profound deafness in childhood. New Engl. J. Med. 363, 1438-1450 pmid:20925546.

Kral, A., Sharma, A., 2012. Developmental neuroplasticity after cochlear implantation. Trends Neurosci. 35, 111-122.

Kraus, N., Micco, A.G., Koch, D.B., Mcgee, T., Carrell, T., Sharma, A., Wiet, R.J., Weingarten, C.Z., 1993. The mismatch negativity cortical evoked potential elicited by speech in cochlear-implant users. Hear. Res. 65, 118-124.

Kujala, T., Tervaniemi, M., Schröger, E., 2007. The mismatch negativity in cognitive and clinical neuroscience: theoretical and methodological considerations. Biol. Psychol. 74, 1-19.

Lang, A.H., Eerola, O., Korpilahti, P., Holopainen, I., Salo, S., Aaltonen, O., 1995. Practical issues in the clinical application of mismatch negativity. Ear. Hear 16, $118-130$.

Lammers, M.J.W., van der Heijden, J.M.G., Pourier, V.E.C., Grolamn, W., 2014. Bilateral cochlear implantation in children: a systematic review and best-evidence synthesis. Laryngoscpopy 124, 1694-1699.

Laneau, J., Wouters, J., Moonen, M., 2006. Improved music perception with explicit pitch coding in cochlear implants. Audiol. Neuro-Otol. 11, 38-52.

Lazard, D.S., Innes-Brown, H., Barone, P., 2014. Adaptation of the communicative brain to post-lingual deafness. Evidence from functional imaging. Hear. Res. 307, 136-143.

Leal, M.C. Shin, Y.., Laborde, M.L., Calmels, M.N., Verges, S., Lugardon, S., Andrieu, S., Deguine, O., Fraysse, B., 2003. Music perception in adult cochlear implant recipients. Acta Oto-Laryngol. 123, 826-835.

Lee, J.S., Lee, D.S., Oh, S.H., Kim, C.S., Kim, J.W., Hwang, C.H., Koo, J., Kang, E. Chung, J.K., Lee, M.C., 2003. PET evidence of neuroplasticity in adult auditory cortex of postlingual deafness. J. Nucl. Med. 44, 1435-1439.

Leino, S., Brattico, E., Tervaniemi, M., Vuust, P., 2007. Representation of harmony rules in the human brain: further evidence from event-related potentials. Brain Res. 1142, 169-177.

Liang, M., Zhang, X., Chen, T., Zheng, Y., Zhao, F., Yang, H., Zhong, Z., Zhang, Z., 
Chen, S., Chen, L., 2014. Evaluation of auditory cortical development in the early stages of post cochlear implantation using mismatch negativity measurement. Otol. Neurotol. 35, e7-e14.

Limb, C.J., Roy, A.T., 2014. Technological, biological, and acoustical constraints to music perception in cochlear implant users. Hear. Res. 308, 13-26.

Limb, C.J., Rubinstein, J.T., 2012. Current research on music perception in cochlear implant users. Otolaryngol. Clin. N. Am. 45, 129-140.

Loizou, P.C., 1999. Introduction to cochlear implants. IEEE Eng. Med. Biol. Mag. 18, $32-42$.

Loizou, P.C., 2006. Speech processing in vocoder-centric cochlear implants. In: Møller, A. (Ed.), Cochlear and Brainstem Implants. Adv Otorhinolaryngol. Basel, Karger, 2006, vol. 64, pp. 109-143.

Lonka, E., Kujala, T., Lehtokoski, A., Johansson, R., Rimmanen, S., Alho, K., Näätänen, R., 2004. Mismatch negativity brain response as an index of speech perception recovery in cochlear-implant recipients. Audiol. Neurootol 9, $160-162$.

Lonka, E., Relander-Syrjänen, K., Johansson, R., Näätänen, R., Alho, K., Kujala, T.M., 2013. The mismatch negativity (MMN) brain response to sound frequency changes in adult cochlear implant recipients: a follow-up study. Acta Oto-Laryngol. 8, 853-857.

Looi, V., Radford, C.J., 2011. A comparison of the speech recognition and pitch ranking abilities of children using a unilateral cochlear implant, bimodal stimulation or bilateral hearing aids. Int. J. Pediatr. Otorhinolaryngol. 75, $472-482$.

Mahjoory, K., Nikulin, V.V., Botrel, L., Linkenkaer-Hansen, K., Fato, M.M., Haufe, S., 2017. Consistency of EEG source localization and connectivity estimates. NeuroImage 152, 590-601.

Makeig, S., Debener, S., Onton, J., Delorme, A., 2004. Mining event-related brain dynamics. Trends Cognitive Sci. 8, 204-210.

Mc Dermott, H.J., Looi, V., 2004. Perception of complex signals, including musical sounds, with cochlear implants. Int. Congr. Ser. 1273, 201-204.

Mc Laughlin, M., Lopez Valdes, A., Reilly, R.B., Zeng, F.G., 2013. Cochlear implant artifact attenuation in late auditory evoked potentials: a single channel approach. Hear. Res. 302, 84-95.

Mc Laughlin, M., Lu, T., Dimitrijevic, A., Zeng, F.G., 2012. Towards a closed-loop cochlear implant system: application of embedded monitoring of peripheral and central neural activity. IEEE Trans. Neural Syst. Rehabil. Eng. 20, 443-454.

Milczynski, M., Wouters, J., van Wieringen, A., 2009. Improved fundamental frequency coding in cochlear implant signal processing. J. Acoust. Soc. Am. 125 (4), 2260-2271.

Miller, J., Ulrich, R., Schwarz, W., 2009. Why jackknifing yields good latency estimates. Psychophysiology 46, 300-312.

Moberly, A.C., 2016. Acoustic cue weighing by adults with cochlear implants: a mismatch negativity study. Ear Hear 37 (4), 465-472. http://dx.doi.org/10.1097/ AUD.0000000000000257, 2016 Jul-Aug.

Moore, B.C.J., Moore, G.A., 2003. Discrimination of the fundamental frequency of complex tones with fixed and shifting spectral envelopes by normally hearing and hearing-impaired subjects. Hear. Res. 182, 153-163.

Mortensen, M.V., Mirz, F., Gjedde, A., 2006. Restored speech comprehension linked to activity in left inferior prefrontal and right temporal cortices in postlingual deafness. Neuroimage 31, 842-852.

Näätänen, R., 1992. Attention and Brain Function. Erlbaum, Hillsdale.

Näätänen, R., 2003. Mismatch negativity: clinical research and possible applications. Int. J. Psychophysiol. 48, 179-188.

Näätänen, R., Escera, C., 2000. Mismatch negativity (MMN): clinical and other applications. Audiol. Neuro-otol. 5, 105-110.

Näätänen, R., Tervaniemi, M., Sussman, E., Paavilainen, P., Winkler, I., 2001. 'Primitive intelligence' in the auditory cortex. Trends Neurosci. 24 (5).

Näätänen, R., Gaillard, A.W., Mantysalo, S., 1978. Early selective-attention effect on evoked potential reinterpreted. Acta Psychol. (Amst) 42, 313-329.

Näätänen, R., Lehtokoski, A., Lennes, M., Cheour, M., Huotilainen, M., Iivonen, A., Vainio, M., Alku, P., Ilmoniemi, R., Luuk, J., Allik, J., Sinkkonen, J., Alho, K., 1997. Language-specific phoneme representations revealed by electric and magnetic brain responses. Nature 385, 30.

Näätänen, R., Picton, T.W., 1987. The N1 wave of the human electric and magnetic response to sound: a review and analysis of the component structure. Psychophysiology 24, 375-425.

Näätänen, R., Kujala, T., Kreegipuu, K., Carlson, S., Escera, C., Baldeweg, T., Ponton, C., 2011. The mismatch negativity: an index of cognitive decline in neuropsychiatric and neurological diseases and in ageing. Brain 134, 3432-3450.

Näätänen, R., Pakarinen, S., Rinne, T., Takegata, R., 2004. The mismatch negativity (MMN) - towards the optimal paradigm. Clin. Neurophysiol. 115, 140-144.

Näätänen, R., Schröger, E., Karakas, S., Tervaniemi, M., Paavilainen, P., 1993. Development of a memory trace for a complex sound in the human brain. Neuroreport 4, 503-506.

Näätänen, R., Paavilainen, P., Rinne, T., Alho, K., 2007. The mismatch negativity (MMN) in basic research of central auditory processing: a review. Clin. Neurophysiol. 118, 2544-2590.

Näätänen, R., Summala, H., 1982. Progress of technology and traffic accidents. J. Occup. Accid. 4, 145-156.

Nager, W., Münte, T.F., Bohrer, I., Lenarz, T., Dengler, R., Möbes, J., Schröder, C., Lesinski-Schiedat, A., 2007. Automatic and attentive processing of sounds in cochlear implant patients - electrophysiological evidence. Restor. Neurol. Neurosci. 25, 391-396.

Naito, Y., Tateya, I., Fujiki, N., Hirano, S., Ishizu, K., Nagahama, Y., Fukuyama, H.,
Kojima, H., 2000. Increased cortical activation during hearing of speech in cochlear implant users. Hear. Res. 143, 139-146.

Nakata, T., Trehub, S.E., Kanda, Y., 2012. Effect of cochlear implants on children's perception and production of speech prosody. J. Acoust. Soc. 131, 1307-1314.

Nogueira, W., Litvak, L., Edler, B., Ostermann, J., Büchner, A., 2009. Signal processing strategies for cochlear implants using current steering. EURASIP J. Adv. Signal Process. 2009, 1-21.

Novitski, N., Tervaniemi, M., Huotilainen, M., Näätänen, R., 2004. Frequency discrimination at different frequency levels as indexed by electrophysiological and behavioral measures. Cognitive Brain Res. 20, 26-36.

Obuchi, C., Harashima, T., Shiroma, M., 2012. Auditory evoked potentials under active and passive hearing conditions in adult cochlear implant users. Clin. Exp. Otorhinolaryngol. 5 (Suppl 1), 6-9.

Olszewski, C., Gfeller, K., Froman, R., Stordahl, J., Tomblin, B., 2005. Familiar melody recognition by children and adults using cochlear implants and normal hearing children. Cochlear Implants.Int. 6, 123-140.

Ortmann, M., Knief, A., Deuster, D., Brinkheetker, S., Zwitserlood, P., et al., 2013. Neural correlates of speech processing in prelingually deafened children and adolescents with cochlear implants. PLoS One 8, e67696.

Ortmann, M., Zwitserlood, P., Knief, A., Baare, J., Brinkheetker, S., am ZehnhoffDinnesen, A., Dobel, C., 2017. When hearing is tricky: speech processing strategies in prelingually deafened childrenand adolescents with cochlear implants having good and poor speech performance. Plos One 12 (1), e0168655. http:// dx.doi.org/10.1371/journal.pone.0168655.

Ortiz-Mantilla, S., Hämäläinen, J.A., Benasich, A.A., 2012. Time course of ERP generators to syllables in infants: a source localization study using age-appropriate brain templates. NeuroImage 59, 3275-3287.

Oxenham, A.J., 2008. Pitch perception and auditory stream segregation: implications for hearing loss and cochlear implants. Trends Amplif. 12, 316-331.

Paavilainen, P., Tiitinen, H., Alho, K., Näätänen, R., 1993. Mismatch negativity to slight pitch changes outside strong attentional focus. Biol. Psychol. 37, 23-41.

Pakarinen, S., Takegata, R., Rinne, T., Huotilainen, M., Näätänen, R., 2007. Measurement of extensive auditory discrimination profiles using the mismatch negativity (MMN) of the auditory event-related potential (ERP). Clin. Neurophysiol. 118, 177-185.

Partanen, E., Kujala, T., Tervaniemi, M., Huotilainen, M., 2013. Prenatal music exposure induces long-term neural effects. PloS One 8, e78946.

Patel, A.D., 2014. Can nonlinguistic musical training change the way the brain processes speech? The expanded OPERA hypothesis. Hear. Res. 308, 98-108.

Peng, S.C., Tomblin, J.B., Turner, C.W., 2008. Production and perception of speech intonation in pediatric cochlear implant recipients and individuals with normal hearing. Ear Hear 29, 336-351.

Perkel, J., Lane, H., Sviersky, M., Webster, J., 1992. Speech of cochlear implant patients: a longitudinal study of vowel production. Acoust. Soc. Am. 91, 2961-2978.

Petersen, B., Gjedde, A., Wallentin, M., Vuust, P., 2013. Cortical plasticity after cochlear implantation. Neural Plast. 2013. Article ID 318521.

Petersen, B., Mortensen, M.V., Hansen, M., Vuust, P., 2012. Singing in the key of life: a study on effects of musical ear training after cochlear implantation. Psychomusicol. Music, Mind Brain 22, 134-151.

Petersen, B., Weed, E., Sandmann, P., Brattico, E., Hansen, M., Derdau, S., Vuust, P., 2015. Brain responses to musical feature changes in adolescent cochlear implant users. Front. Hum. Neurosci. 9.

Ponton, C.W., Don, M., 1995. The mismatch negativity in cochlear implant users. Ear Hear. 16, 131-146.

Ponton, C.W., Don, M., 2004. Cortical auditory evoked potentials recorded from cochlear implant users: methods and applications. In: Cullington, H.E. (Ed.), Cochlear Implants: Objective Measures. Philadelphia, PA, US: WHURR.,"of k", pp. 187-230.

Ponton, C.W., Eggermont, J.J., 2001. Of kitten and kids: altered cortical maturation following profound deafness and cochlear implant use. Audiol. Neurootol 6 363-380.

Ponton, C.W., Eggermont, J.J., Don, M., Waringa, M.D., Kwonga, B., Cunningham, J., Trautwein, P., 2000. Maturation of the mismatch negativity: effects of profound deafness and cochlear implant use. Audiol. Neurootol 5, 67-185.

Roman, S., Canévet, G., Marquis, P., Triglia, J.M., Liegeois-Chauvel, C., 2005a. Relationship between auditory perception skills and mismatch negativity recorded in free field in cochlear-implant users. Hear. Res. 201, 10-20.

Roman, S., Debailleux, S., Canévet, G., Triglia, J.M., Liégeois-Chauvel, C., 2005b. Mismatch negativity and tone discrimination in cochlear-implanted patients. Cochlear Implants Int. 6, 53-55.

Salo, S., Peltola, M.S., Aaltonen, O., Johansson, R., Lang, A.H., Laurikainen, E., 2002 Stability of memory traces for speech sounds in cochlear implant patients. Logop. Phoniatr. Vocol. 27, 132-138.

Sams, M., Paavilainen, P., Alho, K., Näätänen, R., 1985. Auditory frequency discrimination and event-related potentials. Electroencephalogr. Clin. Neurophysiol. $62,437-448$

Sandmann, P., Eichele, T., Buechler, M., Debener, S., Jancke, L., Dillier, N., Hugdahl, K. Meyer, M., 2009. Evaluation of evoked potentials to dyadic tones after cochlear implantation. Brain 132, 1967-1979.

Sandmann, P., Kegel, A., Eichele, T., Dillier, N., Lai, W., Bendixen, A., Debener, S., Jancke, L., Meyer, M., 2010. Neurophysiological evidence of impaired musical sound perception in cochlear-implant users. Clin. Neurophysiol. 121, 2070-2082.

Schierholz, I., Finke, M., Kral, A., Büchner, A., Rach, S., Lenarz, T., Dengler, R. 
Sandmann, P., 2017. Auditory and audio-visual processing in patients with cochlear, auditory brainstem, and auditory midbrain implants: an EEG study. Human Brain Map. 38, 2206-2225.

Senkowski, D., Pomper, U., Fitzner, I., Engel, A.K., Kral, A., 2014. Beta-Band Activity in auditory pathways reflects speech localization and recognition in bilatera cochlear implant users. Hum. Brain Mapp. 35, 3107-3121.

Seppänen, M., Brattico, E., Tervaniemi, M., 2007. Practice strategies of musicians modulate neural processing and the learning of sound-patterns. Neurobiol Learn. Mem. 87, 236-247.

Shannon, R.V., 1983. Multichannel electrical stimulation of the auditory nerve in man. I. Basic psychophysics. Hear. Res. 11, 157-189.

Sharma, A., 2006. Central auditory development in children with cochlear implants: clinical implications. Adv. Oto-Rhino-Laryngol. 64, 66-88.

Sharma, A., Dorman, M.F., Spahr, A.J., 2002. Rapid development of cortical auditory evoked potentials after early cochlear implantation. Neuroreport 13 , 1365-1368.

Sharma, A., Nash, A.A., Dorman, M., 2009. Cortical development, plasticity and reorganization in children with cochlear implants. J. Commun. Disord. 42, 272-279.

Singh, S.S., 2004. Event-related potentials in pediatric cochlear implant patients. Ear Hear. 25, 598-610.

Strait, D.L., Parbery-Clark, A., Hittnera, E., Kraus, N., 2012. Musical training during early childhood enhances the neural encoding of speech in noise. Brain Lang. $123,191-201$.

Strelnikov, K., Rouger, J., Demonet, J.F., Lagleyre, S., Fraysse, B., Deguine, O. Barone, P., 2010. Does brain activity at rest reflect adaptive strategies? Evidence from speech processing after cochlear implantation. Cereb. Cortex 20, $1217-1222$.

Tervaniemi, M., Ilvonen, T., Karma, K., Alho, K., Naatanen, R., 1997. The musica brain: brain waves reveal the neurophysiological basis of musicality in human subjects. Neurosci Lett. 226, 1-4.

Tervaniemi, M., 2009. Musicians-same or Different? The neurosciences and music III-disorders and plasticity. Ann. N.Y. Acad. Sci. 1169, 151-156.

Tiitinen, H., May, P., Reinikainen, K., Näätänen, R., 1994. Attentive novelty detection in humans is governed by pre-attentive sensory memory. Nature 370, 90-92.

Timm, L., Agrawal, D., Viola, C., Sandmann, P., Debener, S., Buchner, A., et al., 2012. Temporal feature perception in cochlear implant users. PloS One 7, e45375. http://dx.doi.org/10.1371/journal.pone.0045375.

Timm, L., Vuust, P., Brattico, E., Agrawal, D., Debener, S., Büchner, A., Dengler, R. Wittfoth, M., 2014. Residual neural processing of musical sound features in adult cochlear implant users. Front. Hum. Neurosci. 8, 181.

Titterington, J., Watson, D., Toner, J., Henry, A., 2003. What can the mismatch negativity (MMN) tell us about short-term auditory sensory memory function in cochlear implanted children? Cochlear Implants Int. 4, 70-72.

Torppa, R., Faulkner, A., Huotilainen, M., Järvikivi, J., Lipsanen, J., Laasonen, M., Vainio, M., 2014a. The perception of prosody and associated auditory cues in early-implanted children: the role of auditory working memory and musica activities. Int. J. Audiol. 53, 1821-1891.

Torppa, R., Huotilainen, M., Leminen, M., Lipsanen, J., Tervaniemi, M., 2014b. Interplay between singing and cortical processing of music: a longitudinal study in children with cochlear implants. Front. Psychol. 5, 1389.

Torppa, R., Salo, E., Makkonen, T., Loimo, H., Pykäläinen, J., Lipsanen, J., Faulkner, A. Huotilainen, M., 2012. Cortical processing of musical sounds in children with Cochlear Implants. Clin. Neurophysiol. 123, 1966-1979.

Trautwein, P.G., Ponton, C.W., Kwong, B., Waring, M.D., 1998. Neurophysiologica and psychophysical measures of duration discrimination in normal-hearing adults and adults with cochlear implants. In: Proc 16th Int Congr Acoustics and 135th Meet Acoust Soc Am, Seattle, pp. 877-878.

Trehub, S.E., Vongpaisal, T., Nakata, T., 2009. Music in the lives of deaf children with cochlear implants. Ann. N. Y. Acad. Sci. 1169, 534-542.

Turgeon, C.C., 2014. An objective auditory measure to assess speech recognition in adult cochlear implant users. Clin. Neurophysiol. 125, 827-835. van Dijk, J.E., van Olphen, A.F., Langereis, M.C., Mens, L.H., Brokx, J.P., Smoorenburg, G.F., 1999. Predictors of cochlear implant performance. Audiology $38,109-116$.

Vavatzanidis, N.K., Mürbe, D., Friederici, A.D., Hahne, A., 2015. The basis for language acquisition: congenitally deaf infants discriminate vowel length in the first months after cochlear implantation. J. Cognitive Neurosci. 27, 2427-2441.

Vavatzanidis, N.K., Mürbe, D., Friederici, A.D., Hahne, A., 2016. The perception of stress pattern in young cochlear implanted children: an EEG study. Front. Neurosci. 10, 68. http://dx.doi.org/10.3389/fnins.2016.00068.

Viola, F.C., De Vos, M., Hine, J., Sandmann, P., Bleeck, S., Eyles, J., Debener, S., 2012. Semi-automatic attenuation of cochlear implant artifacts for the evaluation of late auditory evoked potentials. Hear. Res. 284, 6-15.

Viola, F.C., Thorne, J.D., Bleeck, S., Eyles, J., Debener, S., 2011. Uncovering auditory evoked potentials from cochlear implant users with independent component analysis. Psychophysiology 48, 1470-1480.

Vlastarakos, P.V., Proikas, K., Papacharalampous, G., Exadaktylou, I., Mochloulis, G., Nikolopoulos, T.P., 2010. Cochlear implantation under the first year of age-The outcomes. A critical systematic review and meta-analysis. Int. J. Pediatr. Otorhinolaryngol. 74, 119-126.

Vuust, P. Brattico, E., Glerean, E., Seppanen, M., Pakarinen, S., Tervaniemi, M., Näätänen, R., 2011. New fast mismatch negativity paradigm for determining the neural prerequisites for musical ability. Cortex 47, 1091-1098.

Vuust, P., Brattico, E., Seppanen, M., Näätänen, R., Tervaniemi, M., 2012. The sound of music: differentiating musicians using a fast, musical multi-feature mismatch negativity paradigm. Neuropsychologia 50, 1432-1443.

Wable, J., van den Abbeele, T., Gallégo, S., Frachet, B., 2000. Mismatch negativity: a tool for the assessment of stimuli discrimination in cochlear implant subjects. Clin. Neurophysiol. 111, 743-751.

Watson, D.R., Titterington, J., Henry, A., Toner, J.G., 2007. Auditory sensory memory and working memory processes in chindren with normal hearing and cochlear implants. Audiol. Neurotol. 12, 65-76.

Wie, O.B., 2010. Language development in children after receiving bilateral cochlear implants between 5 and 18 months. Int. J. Pediatr. Otorhinolaryngol. 74, $1258-1266$.

Wilson, B.S., Finley, C.C., Lawson, D.T., Wolford, R.D., Eddington, D.K., Rabinowitz, W.M., 1991. Better speech recognition with cochlear implants (July 1991). Nature 352 (No.6332), 236-238. ISSN 0028-0836.

Wilson, B.S., 2015. Getting a decent (but sparse) signal to the brain for users of cochlear implants. Hear Res. 322, 24-38.

Wilson, B.S., Dorman, M.F., 2008. Cochlear implants: current designs and future possibilities (February 2008). J. Rehab. Res. Dev. 45 (No.5), 695-730. ISSN 0748-7711.

Wilson, B.S., Lawson, D.T., Finley, C.C., Wolford, R.D., 1993. Importance of patient and processor variables in determining outcomes with cochlear implants. J. Speech Hear Res. 36, 373-379.

Wilson, B.S., Dorman, M.F., 2007. The surprising performance of present-day cochlear implants. IEEE Trans. Biomed. Eng 54, 969-972.

Winkler, I., Denham, S.L., Nelken, I., 2009. Modeling the auditory scene: predictive regularity representations and perceptual objects. Trends Cogn. Sci. 13, $532-540$.

Yabe, H., Saito, F., Fukushima, Y., 1993. Median method for detecting endogenous event-related brain potentials. Electroenceph Clin. Neurophysiol. 87, 403-407.

Zatorre, R.J., Salimpoor, V.N., 2013. From perception to pleasure: music and its neural substrates. PNAS 110, 10430-10437.

Zeng, F.G., 2004. Trends in cochlear implants. Trends Amplif. 8, 1-34.

Zhang, F., 2011. Mismatch negativity and adaptation measures of the late auditory evoked potential in cochlear implant users. Hear. Res. 275, 17-29.

Zhang, F., Benson, C., Fu, Q.-J., 2013a. Cortical encoding of pitch contour changes in cochlear implant users: a mismatch negativity study. Audiol. Neuro-Otol. 18 (5) http://dx.doi.org/10.1159/000351802.

Zhang, F., Benson, C., Cahn, S.J., 2013b. Cortical encoding of timbre changes in cochlear implant users. J. Am. Acad. Audiol. 24, 46-58. 